\title{
La cobertura de las noticias científicas en diarios digitales argentinos (2017-2018)
}

\section{Guillermo Damián Spina}

spinaguillermo@gmail.com

Departamento de Humanidades y Ciencias Sociales, Universidad Nacional de La Matanza.

\section{Cecilia Beatriz Díaz}

diaz.ceciliab@gmail.com

Departamento de Humanidades y Ciencias Sociales, Universidad Nacional de La Matanza.

Fecha de finalización del trabajo: 5 de noviembre de 2019.

Recibido: 14 de noviembre de 2019

Aceptado: 11 de junio de 2020.

DOI: https://doi.org/10.26422/aucom.2020.0901.spi

\section{Resumen}

La comunicación pública de la ciencia (CPC) aborda el conjunto de informaciones que tienen contenidos científicos destinados al público generalista como modos de socialización de este conocimiento especializado. En este plano, la cobertura periodística sobre temas científicos adquiere relevancia en tanto que los medios masivos de comunicación construyen y refuerzan representaciones en torno a los investigadores, la ciencia y su carácter social.

Ante la irrupción de nuevos soportes informativos, analizamos la comunicación pública de la ciencia en los diarios digitales de Argentina (2017-2018) en las dimensiones clave de la producción periodística, tales como el tipo de información y el tratamiento de las fuentes según las temáticas científicas.

A partir del análisis de contenido sobre una muestra de semana construida, se exponen resultados que tienen como fin conformar un mapeo de situación de la cobertura periodística sobre ciencia en los diarios de mayor representatividad de las distintas regiones del territorio nacional. Esto implica explorar y determinar regularidades y particularidades en el volumen y despliegue informativo sobre las disciplinas científicas.

$\mathrm{Al}$ respecto, el relevamiento realizado evidencia que el tratamiento de fuentes sobre temas de ciencia se encuentra poco diversificado y que la CPC no es valorada en su nivel de despliegue informativo, aunque presenta matices de acuerdo con las temáticas científicas tratadas.

Palabras clave: comunicación pública de la ciencia, periodismo científico, diarios digitales, fuentes periodísticas. 


\section{Scientific news coverage in Argentine online newspapers (2017-2018)}

\section{Abstract}

The public communication of science entails all information with scientific content destined to be read by the general public and how this specialized knowledge is disseminated in society. The coverage of scientific topics in news outlets is therefore relevant, since mass communication media depicts and reinforces representations of scientists, science, and its social character.

Given the emergence of new information media, we analyze the public communication of science in online newspapers in Argentina (2017-2018), taking into account crucial aspects of journalistic work, such as the type of information and the use of sources depending on the topic.

Through a content analysis of a constructed week sample, our results map the situation of scientific news coverage in the most representative newspapers from different parts of the country. This means exploring and determining both regularities and particularities in the volume and spread of information on various scientific disciplines.

In doing so, the study reveals that, in scientific news coverage, the use of sources is poorly diversified, while the public communication of science is not valued for its role in disseminating information, although these results vary depending on the topic being covered.

Keywords: public communication of science, scientific journalism, online newspapers, journalistic sources

\section{A cobertura de notícias científicas nos jornais digitais argentinos (2017-2018)}

\section{Resumo}

A Comunicação Pública da Ciência (CPC) refere-se ao conjunto de informações com conteúdo de caráter científico para o público em geral, no intuito de disseminar esse conhecimento especializado. Neste campo de informação, a cobertura jornalística sobre assuntos científicos possui grande importância, pois a mídia de massa constrói e reforça representações em torno de pesquisadores, da ciência e de seu caráter social.

Diante do surgimento de novas mídias de informação, analisamos a comunicação pública da ciência nos jornais digitais da Argentina (2017-2018) nas principais dimensões da produção jornalística, como o tipo das informações publicadas e suas referidas fontes, conforme os temas científicos.

A partir da análise de uma mostra de conteúdos referente a um período de publicações, são apresentados resultados que visam formar um mapeamento da cobertura jornalística da ciência nos principais jornais em diferentes regiões do território nacional. Isso implica explorar e determinar regularidades e particularidades no volume e no modo de apresentar as publicações sobre assuntos científicos.

Nesse sentido, a pesquisa realizada mostra que o tratamento de fontes sobre temas científicos não é muito diversificado e que o CPC não é valorizado em seu nível de implantação de informações, embora apresente nuances de acordo com os temas científicos abordados.

Palavras chave: comunicação em ciências públicas, jornalismo científico, jornais digitais, fontes jornalísticas. 
Austral Comunicación

Volumen 9, número 1 (Junio de 2020): 5-43. ISSN 2313-9129

\section{Introducción}

La "Declaración de la Ciencia y el uso del Conocimiento científico" de la UNESCO (1999) expresó que el conocimiento científico debe ser compartido y que en esa tarea es necesaria la cooperación auténtica entre Gobiernos, sociedad civil, sector empresarial y científicos. De allí surgen modos de socialización del conocimiento especializado hacia el público masivo que conforman el campo de estudio de la comunicación pública de la ciencia (CPC).

Esto implica que la CPC aborda cualquier sistema susceptible de ser vehículo de comunicación científica para un público masivo, con el fin de provocar la apropiación cultural de contenidos científicos de acuerdo con las particularidades de cada país (Calvo Hernando, 2003). Por esa razón, la CPC observa y aplica técnicas de la publicidad, el espectáculo, las relaciones públicas, la divulgación tradicional y el periodismo, entre otras. ${ }^{1}$

La divulgación y el periodismo científico se ubican dentro del amplio campo de la comunicación científica, y este ámbito de la comunicación reúne aquellos discursos cuyo objetivo es la ciencia y la tecnología, portadores de conocimientos como también de problemáticas relacionadas con el mundo de la ciencia. Los términos "divulgación" y "periodismo científico" a menudo se han utilizado indistintamente, lo que ha generado confusiones, ambigüedades y discusiones al respecto. Tal como afirma Eliseo Verón (1998)

\section{es necesario distinguir claramente todos estos diferentes discursos acerca de la ciencia y no confundir la actividad discursiva de producción del saber -destinado a otros miem- bros de la comunidad científica- con los discursos sobre las condiciones de esta produc- ción y sus resultados que van dirigidos a otros sectores de la sociedad (p. 99).}

Sin duda, la transformación de los medios de comunicación y la ampliación del sistema educativo se tradujeron en nuevas formas de comunicar la ciencia y la valoración sobre estas acciones. Pero es el periodismo uno de los lenguajes más revisados en el objetivo de lograr que la ciencia y la tecnología sean incorporadas como cuestiones socialmente relevantes para la ciudadanía.

Claramente, el eje de discusión se traslada a los niveles de conocimiento social sobre la ciencia y los factores culturales, sociales y políticos que los afectan. El concepto de "alfabetización científica ciudadana" (Miller, Pardo y Niwa, 1998) se desarrolló como parámetro que permitía comparar las repercusiones de la ciencia y la tecnología en los individuos y la sociedad según el país. Sus dimensiones fueron: 1) dominio del vocabulario de conceptos científicos básicos; 2) comprensión del proceso de investi-

\footnotetext{
Es necesario aclarar que el campo de la CPC excluye la comunicación entre especialistas con fines docentes o de investigación, ya que se trata de un ámbito que obedece a otros propósitos.
} 
Guillermo Damián Spina, Cecilia Beatriz Díaz

La cobertura de las noticias científicas en diarios digitales argentinos (2017-2018)

gación científica; y 3) repercusiones del sector en un sistema político determinado o en varios países y si sus experiencias científicas y tecnológicas son esencialmente comunes. Con estos parámetros, las desigualdades de conocimiento y apropiación de los contenidos científicos revelaban falencias en los sistemas educativos y en los medios de comunicación. Pero ¿todos los ciudadanos deben saber de ciencia?

Para Miller, Pardo y Niwa (1998), la CPC debe orientarse a formar "cultura científica", es decir, contribuir a la comprensión del contenido sustantivo, de las prácticas metodológicas de la ciencia para aprehender valores, preferencias y expectativas hacia la ciencia como centro de la sociedad moderna. En este sentido, el periodismo científico fue llamado a elevar el nivel de comprensión del público sobre la ciencia (Cortassa, 2011). Esta especialización de la labor periodística se caracteriza, desde entonces, por el abordaje de temas que tienen componentes científicos y tecnológicos para divulgarlos a la sociedad. De ese modo, visibiliza el desarrollo científico que se lleva a cabo en universidades, institutos y laboratorios para intentar la apropiación social de sus beneficios. En efecto, requiere de la consulta de fuentes científicas y de estrategias informativas diferentes a otras especializaciones periodísticas.

Entre 1960 y 1980, en la CPC tuvo vigencia el paradigma de la "alfabetización científica" (Bauer, 2007) para reducir el déficit cognitivo del público. Hasta la década del '90, se produjo un viraje hacia la "comprensión pública de la ciencia", que establecía una correlación entre la falta de valorización de la ciencia y el desconocimiento del público, por lo que el periodismo científico no solo debía educarlo, sino también atraerlo a estas temáticas.

A mediados de los '90, el paradigma "ciencia y sociedad" (Bauer, 2007) revierte el diagnóstico al entender que el déficit de conocimiento se concentra en las instituciones científicas y en los expertos sobre el público y no al revés. A partir de entonces, se desarrollan los departamentos de prensa y difusión de las instituciones científicas para fomentar la repercusión mediática. Asimismo, la propuesta de este paradigma fue la promoción de la participación en las decisiones sobre cuestiones científico-tecnológicas. En esa línea, las nuevas corrientes de la ciencia y la tecnología (СyT) abogan por la constitución del "ciudadano científico", un actor que intervenga en la gobernanza de la ciencia y en el que participen diferentes intereses en juego (Irwin y Michael, 2003).

En función de esta trayectoria de los paradigmas de la CPC, la cobertura periodística sobre temas científicos adquiere relevancia en tanto que los medios masivos de comunicación construyen y refuerzan representaciones en torno a los investigadores, la ciencia y su carácter social. Para estudiar el tipo y las características de la información, resulta necesario analizar sus atributos y propiedades desde múltiples perspectivas. En efecto, la calidad periodística está condicionada por numerosos factores, tales como criterios de noticiabilidad, análisis de los contenidos, credibilidad, condiciones 
laborales de los periodistas, perfil de los directivos o empresarios y relaciones con el entorno, entre otros.

Una dimensión de esas relaciones puede inferirse por el tratamiento de las fuentes, dado que conforman un componente básico del discurso mediático con una capacidad de determinar el contenido y la orientación temática de la cobertura informativa. También constituye un elemento clave para analizar la calidad y el rigor profesional de la producción periodística.

En Argentina, desde mediados de 2006, se evidencia una consolidación de los temas científicos en la agenda periodística de los principales diarios argentinos, aunque se observan deficiencias en la pluralidad de fuentes y jerarquización noticiosa (SECYT, 2006).

En otro estudio de carácter cualitativo sobre los diarios editados en la prensa de la Ciudad de Buenos Aires, Palma (2012) analiza las representaciones de los investigadores y la ciencia, donde concluye que los "vicios" del periodismo generalista -tales como estereotipos, chauvinismo y trivialidades- redundan en una cobertura lejana a la misión adjudicada al periodismo científico. Un caso particular lo constituye la biomedicina, que es abordada en medios digitales españoles bajo las mismas lógicas -fuentes, géneros y lenguajes- que los medios tradicionales, según Moreno Espinosa (2010).

Es interesante destacar que la aparición de internet fomentó expectativas respecto a sus potencialidades sobre el acceso a la producción científica. Sin embargo, estudios pioneros sobre la prensa online de España diagnosticaban una falta de delimitación de los contenidos científicos, espectacularización y poca diversidad de fuentes (Marín Murillo y Armentia Vizuete, 2002). Estas características se vuelven tendencias en la prensa escrita argentina.

Otro estudio señala que la cobertura de los diarios generalistas nacionales ${ }^{2}$ depende de fuentes documentales -tales como papers y hasta gacetillas de prensa que algunos institutos contemplan-, pero no hay contacto directo con los investigadores, por lo que los modos de presentación de la información se concentran en el género de noticia (Spina, 2013).

Por su parte, Bauer (2014) observa que el periodismo científico encuentra restringida su acción con el desarrollo de la comunicación de la ciencia. En su estudio, identifica como tendencias las condiciones laborales de los periodistas y la proliferación de actores vinculados a la ciencia y a la tecnología, sin coordinación y en competencia por lograr atención.

Estas observaciones resultan ser una constante en el mapeo de situación de las noticias sobre CPC que fueron publicadas en los diarios argentinos impresos de mayor

\footnotetext{
Popularmente se los conoce como "nacionales", pero son producidos y editados en la Ciudad Autónoma de Buenos Aires y Gran Buenos Aires para el resto del país.
} 
Guillermo Damián Spina, Cecilia Beatriz Díaz

La cobertura de las noticias científicas en diarios digitales argentinos (2017-2018)

distribución y de contenidos generalistas durante 2015, donde prima la temática salud, las noticias no son firmadas y hay un correlato entre actividad económica de la región y disciplina científica visibilizada (Spina y Díaz, 2016).

$\mathrm{Al}$ respecto, este artículo actualiza la pregunta: ¿qué fuentes se utilizan para la cobertura periodística sobre ciencia en los diarios digitales argentinos? ¿El tratamiento de fuentes se altera en función de la temática científica en cuestión?, entendiendo al tratamiento de la fuente por su naturaleza, tipo, cantidad y procedencia en el marco de la producción periodística, dada por el género y el agente de la producción.

De esta forma, el presente artículo intenta exponer un mapeo de situación sobre el tipo de producción de la información científica publicada, el género utilizado para abordarla y el tratamiento de fuentes que se aplican en las noticias sobre CPC publicadas en el periodo comprendido entre el 3 de julio de 2017 y el 3 de junio de 2018 en la prensa digital argentina. ${ }^{3}$ Se trata de un relevamiento hecho sobre un corpus de veinticinco diarios digitales argentinos, con tres actualizaciones al día y mediante la metodología de semana construida (Krippendorf, 1990; Stempel, 1989).

En esa dirección, los objetivos específicos se orientan a caracterizar el tratamiento de fuentes en las noticias científicas por parte de las redacciones periodísticas a lo largo del país y a describir el despliegue informativo que recibe la CPC en la prensa generalista.

En suma, el artículo se estructura, en primer lugar, a partir del desarrollo del marco teórico sobre la producción de las noticias y el tratamiento de las fuentes en la prensa gráfica. Luego, se detallan las características metodológicas del estudio y los resultados de las variables relativas a producción, fuentes y temáticas científicas. Finalmente, se presentan las inferencias a las que pueden arribarse a partir del análisis.

\section{La producción de las noticias}

No todos los hechos son noticia ni todas las noticias presentan los mismos niveles de producción informativa. Por eso, su análisis es una tarea que revela la ponderación que la empresa periodística realiza para forjar el producto que finalmente es lanzado al mercado de la información.

Entendemos que la noticia es la divulgación de un suceso (Martini, 2000) que implica "una particular construcción del discurso de la información que narra eventos factuales generalmente públicos" (Escudero Chauvel, 1997, p. 73). Si llevamos este concepto a las temáticas de ciencia y tecnología, la noticia científica en particular es la

\footnotetext{
Este trabajo se inscribe en el proyecto de investigación en curso "Análisis de la comunicación pública de la ciencia en los diarios argentinos" (CyTMa 2 C2-HUM037), presentado en el Departamento de Humanidades y Ciencias Sociales de la Universidad Nacional de La Matanza (UNLaM), bajo la dirección de Guillermo Damián Spina e integrado por Cecilia Beatriz Díaz y Pablo Daniel Farinato.
} 
"narración de un descubrimiento, un avance o una idea científica nueva, que interesa al receptor y que se presente de forma atractiva" (Gregori, 2004). Es decir, constituye una información especializada dirigida a un público masivo, cuyos intereses y competencias pueden no ser cercanas, pero contienen relevancia pública.

Al respecto, Martí Domínguez (2004) señala que la producción de la noticia científica tiene diferencias sustanciales con las generalistas, tales como la prudencia para la publicación de novedades de última hora y el impacto de portada; su selección por parte de los diarios no obedece a la jerarquización dentro de una disciplina científica ni a la exigencia de incluir estrategias explicativas para facilitar su comprensión. Esto no implica dejar de lado la corrección y la rigurosidad para utilizar los términos teóricos y técnicos de la investigación científica ni la creatividad para ampliar -o transformar- los géneros informativos de los medios masivos.

Dadas estas características, entendemos que los ítems noticiosos a relevar, para ser considerados científicos en cualquiera de las disciplinas posibles, deben dar cuenta de un proceso de investigación científica, ya sean avances, hallazgos provenientes de la indagación bibliográfica, documental o de trabajos de campo tanto en la ciencia básica como en la aplicada.

Pero no cualquier hecho vinculado a la $\mathrm{CyT}$ adquiere el rango de noticia. En efecto, la producción noticiosa implica la selección de hechos relevantes por criterios de noticiabilidad. Entre ellos, pueden distinguirse los parámetros de novedad (la noticia debe tratar sobre nuevos acontecimientos), la actualidad (los hechos deben ser recientes), la presuposición (los periodistas deben suponer que los lectores pueden no haber leído la información previa y tal vez que necesiten un resumen como antecedente), relevancia (los acontecimientos deben ser de importancia para el lector), desviación y/o negatividad, proximidad y consonancia (la noticia debe estar en relación con normas y valores socialmente compartidos). ${ }^{4}$ Según Teun van Dijk (1990), "reflejan los valores económicos, sociales e ideológicos en la reproducción del discurso de la sociedad a través de los medios de comunicación” (p. 175). Por ello, el estudio de la cobertura periodística nos permite inferir la relevancia mediática de las noticias científicas.

Sin duda, la importancia editorial puede observarse también en su visibilidad y jerarquización, pero en este trabajo nos centraremos en los indicadores de desarrollo informativo de noticias sobre ciencia tales como la producción de la noticia, el género periodístico y el tratamiento de fuentes que recibe la CPC. Entendemos que "las rutinas productivas de los medios incluyen la recolección de material informativo y su

\footnotetext{
En otra tipología de noticiabilidad, Martini y Luchessi (2004) agregan la excepcionalidad, la imprevisibilidad, el interés público, la revelación de lo oculto, la gravedad de los hechos y el interés de los medios y de las fuentes informativas. Este último aspecto revela una dimensión clave de la producción periodística en el marco de sus relaciones sociales e institucionales que se consideran en este estudio.
} 
Guillermo Damián Spina, Cecilia Beatriz Díaz

La cobertura de las noticias científicas en diarios digitales argentinos (2017-2018)

procesamiento, para reestructurarlo de acuerdo con los valores relativos de la noticia, al producto, al formato o al medio" (Wolf, 1987, p. 65).

$\mathrm{Al}$ respecto, son varios los autores que coinciden en una tendencia generalizada en los medios de comunicación: la homogeneización de la información científica, ya sea por "mimetismo" (De-Semir, 2000) o producto del movimiento circular de la información publicada (Bourdieu, 2003). Es decir, los medios cubren los mismos temas a los fines de competir, y como referencia en la agenda periodística internacional replican a diarios como The New York Times, The Times o Le Monde, entre otros.

Otro indicador de la producción periodística lo constituye la firma responsable de la noticia en tanto que específica si la información es una elaboración de un periodista del medio, allí radica su autoría o si el crédito de la producción recae en otra figura. En ese sentido, un actor recurrente son las agencias de noticias -nacionales o internacionales, estatales o privadas-, cuya emisión de despachos informativos se dirige a innumerables medios informativos, por lo cual la decisión editorial se limita a la selección, pero no a la indagación y al abordaje del hecho noticioso. También los medios cuentan con productos periodísticos más exclusivos dados por corresponsales especiales y/o divulgadores científicos, quienes anotician sobre novedades que pueden despertar el interés del lector.

En este sentido, los géneros periodísticos utilizados son indicadores de desarrollo informativo. Para Bajtín (1979), los géneros discursivos son adaptaciones del lenguaje a situaciones de comunicación particulares, por lo que presentan rasgos estables vinculados a las condiciones de producción, circulación y recepción de los textos. En este caso, en el ámbito periodístico, el uso de diferentes géneros (noticia, reportaje, entrevista e informe) está determinado por la disponibilidad de recursos para su elaboración y la intencionalidad de presentar abordajes de calidad que se diferencien de otros medios. Entre esos recursos se encuentra el acceso a las fuentes informativas.

En efecto, en la práctica periodística, la fuente es "el punto de partida de todo proceso comunicativo -informativo o cognoscitivo-" (Chimeno Rabanillo, 1997, p. 45). Se trata de personas (particulares) o grupos de personas (asociaciones, empresas o instituciones) que suministran informaciones al periodista para que este, al publicarlas, las convierta en noticia (Gans, 1979). También son fuentes los documentos o depósitos de información que pueden ser consultados por el profesional: archivos, libros, revistas y publicaciones especializadas que le llegan en distintos soportes. Es decir, una división clásica de fuentes incluye tanto las orales o personales como las escritas o documentales.

El estudio de las fuentes informativas resulta esencial para analizar la competencia mediática a la hora de construir la realidad social. Las fuentes constituyen un componente básico del proceso de producción y selección periodística que, por lo tanto, son 
capaces de condicionar decisivamente el contenido (agenda) y el enfoque (framing) de la cobertura informativa. Para Grossi (2007), el estudio de la gestión de fuentes revela la legitimidad del sistema democrático, la distribución del poder, la construcción de consensos, la influencia en la toma de decisiones y la percepción social de la realidad política.

Por ello, en las últimas décadas, se desarrolla el interés por el análisis de las fuentes hasta convertirse en un importante ámbito de investigación científica en periodismo. Desde una perspectiva profesional, el tratamiento de fuentes remite directamente a dos conceptos clave en periodismo: la credibilidad y la calidad (Dimitrova y Strömbäck, 2009; Franklin y Carlson, 2011).

Sin embargo, la accesibilidad a la diversidad de fuentes es un aspecto problemático en el análisis, especialmente cuando se trata de noticias científicas. Para Ribas (2002), los criterios noticiosos de la importancia y el interés están estrechamente vinculados a las fuentes, porque los medios se encuentran condicionados por el grado de poder institucional que tienen ciertas organizaciones en relación a otras, o en el impacto de acuerdo conl país del que sea originaria la información. Ribas (2002) aclara que si bien la cultura científica es percibida por el periodismo como universal, "la ciencia que proviene de los países no existentes desde el punto de vista de la información es mucho más difícil que aparezca" (p. 8).

Al respecto, Miguel Rodrigo Alsina (2003) sostiene que el funcionamiento de las fuentes lleva a "una institucionalización de determinadas fuentes que son actores sociales y tienen una especie de derecho de acceso semiautomático a los medios de comunicación" (p. 61) en detrimento de otros sectores. Estas relaciones entre las líneas editoriales de los medios, los periodistas, los investigadores y las instituciones -públicas y privadas, nacionales y extranjeras- permiten comprender el tratamiento de las temáticas científicas más publicadas y, eventualmente, identificar agentes de la construcción de las representaciones sobre el conocimiento científico y de su importancia social.

En las sociedades modernas, la mayoría de las fuentes de información aspiran a influir en los relatos periodísticos, incluso a los fines de "prefabricar un relato de los hechos" (Mayoral Sánchez, 2005, p. 14), o bien "configuran y codifican el mensaje desde el prisma perspectivita que le imponen sus limitaciones naturales" (Chimeno Rabanillo, 1997, p. 46) que conlleva a sesgos informativos. En ese plano, la rigurosidad profesional del periodista científico adquiere importancia.

Los intereses y las perspectivas de los medios y de los periodistas entran en una sinergia que configura, en términos de Mc Quail (1998), "un proceso bilateral muy activo"; donde "los medios están en constante búsqueda de contenidos adecuados y los contenidos siempre están buscando una forma de convertirse en noticias" (p. 192). 
Guillermo Damián Spina, Cecilia Beatriz Díaz

La cobertura de las noticias científicas en diarios digitales argentinos (2017-2018)

Ante lo expuesto, y teniendo en cuenta que las fuentes no siempre son solo abastecedoras de información, sino que, en algunos casos, presentan intenciones de indicar temáticas o interpretaciones, ¿cómo es y/o debe ser la relación entre el medio periodístico y la fuente de la noticia científica cuando existe una asimetría de saberes? Furio Colombo (1995) plantea que el grado de especialidad de la noticia y la autoridad de la fuente "impiden o desaconsejan la verificación" (p. 96) por parte del periodista. Esta visión ubica a la fuente científica en una instancia superior al periodista y al medio de comunicación, donde este debe subordinarse al científico y acatar su información; por más riesgos de manipulación que eso conlleve, da valor a la noticia y es respetada por la comunidad.

Respecto a esta comunicación asimétrica, Alcíbar Cuello (2004) alerta que el intermediario debe acercar la ciencia al público, pero sin que esto implique "la sumisión a los cánones que dicta la autoridad científica, cercenando la capacidad crítica del periodista para cuestionar la credibilidad de sus fuentes" (p. 49). Más aún, especifica que este escenario mantiene activa la tensión pedagógica presente entre científicos y periodistas.

En otras palabras, el rol de los periodistas se basa en sostener esas relaciones con las fuentes y procesar "información corta, sintética y clara, de acuerdo con la actualidad y las características de un lector no especializado" (Fayard, 1993, p. 34).

Estas indagaciones refuerzan que la noticia es un campo de disputa de las interpretaciones entre fuentes y periodistas. Para Bourdieu (1996), el periodismo es un campo autónomo, ya que tiene leyes propias por las que se rige (actualidad, rituales, fuentes, impacto, condiciones de escritura y realidad), cuenta con estrategias propias para su comunicabilidad (géneros periodísticos) y tiene una efectividad social en la formulación de narrativas sociales (la manera en cómo devenimos relato público) y en la producción del sentido social (la agenda pública). Las condiciones de producción del periodismo constituyen los límites y las posibilidades de su comunicación.

En tal sintonía, la encuesta realizada por Carmen del Puerto (2000), y en respuesta a la pregunta correspondiente sobre las fuentes del periodismo científico, se sostiene que "las principales fuentes son los protagonistas de la información y sus publicaciones especializadas" (p. 87). En este sentido, se reivindica el trabajo de los gabinetes o departamentos de prensa como fuentes muy utilizadas, pero que requieren del periodista científico la corroboración de la información recibida con otras fuentes, para así evitar ser parte de una campaña sin sustento científico y poner en riesgo la credibilidad del medio.

Por otra parte, para los sociólogos Jay Blumler y Michael Gurevitch, los científicos y los periodistas participan en lo que denominan shared culture, es decir, unas normas compartidas que rigen sus interacciones y que llevarían a la cooperación más que al conflicto, en donde queda establecido que ambos se necesitan mutuamente (Dunwoody, 1986, p. 13). Al respecto, Malen Ruiz de Elvira (1990) clasifica a los 
Austral Comunicación

Volumen 9, número 1 (Junio de 2020): 5-43. ISSN 2313-9129

científicos en dos clases fundamentales. Por un parte, se encuentran los del "entorno inmediato", cuyo vínculo con el periodista es habitual para mantenerse actualizado de novedades en un campo de saber específico. Por otra parte, los científicos de otros países, que son entrevistados en eventos de su especialidad, en su lugar de trabajo, ante la publicación de artículos importantes o cuando participan en hechos noticiables. Estas vinculaciones se revelan en el tipo y en la procedencia de las fuentes que los periodistas publican.

Un aspecto clave para el vínculo entre la fuente científica y el periodista y/o medio es la credibilidad de los científicos. Para Dunwoody (1986), los periodistas analizan "el estatus dominante, las credenciales administrativas, y el contacto previo con los medios" (p. 13), mientras que un factor diferenciador es la pertenencia institucional del científico en el ámbito privado o público.

En los estudios de la CPC en Argentina, Cortassa (2012) señala que para los periodistas científicos la calidad de un informante se distingue a partir "del prestigio de la institución a la que pertenece el científico, su inserción en el sistema de publicaciones y el reconocimiento de sus pares" (p. 47). A estas cuestiones le agrega indicadores, como la restricción a sus límites disciplinares y el ajuste al conocimiento paradigmático.

En el tratamiento de las fuentes informativas, el periodismo científico debe considerar que "para la mayor parte del público la realidad en materia científica es lo que lee en la prensa" (Nelkin, 1990, p. 85), por lo que debe proveer el conocimiento necesario para la comprensión de la información científica en la construcción de un sentido crítico orientado a la toma de decisiones.

Bajo ese imperativo, la fuente consultada por el periodismo científico contribuye a garantizar la calidad de la información publicada. Para su selección, el profesional requiere de un nivel de conocimiento aceptable de los antecedentes culturales para abordar los diferentes temas con cierta destreza o, en su defecto, indagar en referentes disciplinares (fuentes documentales o humanas, particulares o colectivas) para el tratamiento periodístico.

\section{Materiales y métodos}

La investigación que da origen a este trabajo releva los ítems noticiosos sobre ciencia y tecnología en tanto jerarquización, visibilidad y tratamiento de fuentes. En ese sentido, entendemos por "ítem noticioso científico" al conjunto de elementos verbales y visuales continuos referidos a un mismo tópico, presentado en cualquier género periodístico informativo -exceptuando las notas de opinión en cualquiera de sus variantes genéricas- y que incluye resultados de investigaciones en todas las áreas de conocimiento o aborda resultados relacionados con las ciencias (Bucchi y Mazzolini, 2003). 
Guillermo Damián Spina, Cecilia Beatriz Díaz

La cobertura de las noticias científicas en diarios digitales argentinos (2017-2018)

A su vez, de los sitios web de los diarios se analizará tanto lo que se publica en su home como todos los suplementos y secciones que sean realizados y editados por el mismo medio. ${ }^{5}$

Dado que el objeto de este estudio es un producto de comunicación masiva, se optó por el método del análisis de contenido, ya que es el que nos permite inferir el funcionamiento del objeto (ítem noticioso) y predecir su mecanismo de influencia (Igartua y Humanes, 2004).

Asimismo, y siguiendo a Neuendorf (2002), es un procedimiento sistemático ideado para examinar el contenido de una información y adopta como unidad de análisis al mensaje. A través de esta metodología, se pueden categorizar de manera sistemática los contenidos de la comunicación, utilizando para ello métodos estadísticos (Riffe, Lacy y Fico, 2005), lo que, a su vez, habilita a identificar las relaciones entre sus distintas características.

Para la definición de la muestra representativa del universo de noticias de CPC publicadas en los diarios digitales argentinos, se recurrió a la técnica de la semana construida (Stempel, 1989; Krippendorf, 1990), la cual configura una selección aleatoria y estratificada que ha presentado evidencias estadísticas que avalan su efectividad para el análisis de contenido frente a, por ejemplo, un muestreo aleatorio simple (Lacy, Robinson y Riffe, 1995), sumado a que ha sido la técnica utilizada en trabajos anteriores (SECYT, 2006; Spina, 2013; Spina y Díaz, 2018b; Spina et al., 2018).

En cuanto a la conformación del corpus, es decir, las ediciones de los diarios representativos de las regiones, se determinó a partir del establecimiento de una fecha aleatoria y, por ende, la semana construida en tanto muestra del año. De acuerdo con Neuendorf (2002), las variaciones diarias y mensuales son factores importantes para tener en cuenta cuando se conduce un análisis de contenido.

El método elegido para el análisis de contenido es el relevamiento de casos, el cual se convierte en una muestra representativa estratificada-sistemática de las versiones digitales de cada diario.

Así, el año calendario se dividió en dos bloques de seis meses, seleccionando al azar una fecha de partida para cada periodo. Después, y usando un intervalo de 4-5 semanas, se seleccionó la siguiente semana, que corresponde al siguiente mes. Así, cada mes del año estudiado se encuentra representado por la muestra con una fecha contemplada en la primera semana de cada uno. De este modo, fueron seleccionados doce días por cada mes del año más los dos domingos iniciales de cada semestre analizado, de manera que la elección de los dos días complementarios sea aleatoriamente concordante con cada semestre de la muestra. De esta forma, se evita algún sesgo de subjetividad o intencionalidad sobre la muestra y se completan las semanas construidas.

Se excluye de la muestra toda publicación que no sea de la editorial analizada y aparezca tanto como un espacio publicitario (formal o no tradicional) como las ventanas pop up que puedan abrirse al navegar la web. 
Respecto a la selección de los diarios, en primer lugar se subdividió al país en seis regiones: Patagonia, Ciudad Autónoma de Buenos Aires, Centro, Cuyo, Noroeste y Noreste. En cada una de ellas se determinó cuáles eran los diarios representativos por circulación, historia y niveles de venta, para así lograr que los resultados de la investigación sean federales. ${ }^{6}$

Por otra parte, la dinámica de edición de los diarios digitales -de actualización constante en contraste con las versiones graficas, que cuentan con ediciones claramente establecidas por cada medio- exigió tomar tres muestras diarias de cada sitio para detectar con mayor agudeza todo lo que puede publicarse a lo largo de la fecha asignada por la semana construida.

Los horarios de dicho muestreo fueron 9,14 y 19 horas a los fines de tener registros cada cinco horas, sobre todo considerando la rutina de trabajo de los diarios. ${ }^{7}$ En contrapartida, los ítems encontrados que correspondían a otros días no fueron considerados, y los que fueron analizados en una de las actualizaciones no conformaron la muestra, salvo que el ítem haya sido editado por el diario, es decir, cualquier modificación en el título, bajada, complementación audiovisual o extensión del texto configura un nuevo ítem.

La totalidad de las capturas de pantallas de cada uno de los diarios que conformaron el corpus de análisis se realizó mediante la utilización de una aplicación que generó un archivo de imagen en formato JPG, el cual no afectó el diseño original de cada editorial, permitiendo, además, que pueda registrarse la foto de cada diario y sección a la vez, de manera que el tiempo de registro sea similar y, por lo tanto, comparable entre los distintos medios analizados.

A los fines de los alcances de este artículo, se describen las variables: a) temática científica (V09); b) producción de la información (V07); c) tipo de información (V08); d) naturaleza de la fuente (V22); e) cantidad de fuentes (V23); f) tipo de fuente (V24); y g) procedencia de la fuente (V25).

En primer lugar, con la variable temática científica (V09), se clasificó el ítem noticioso analizado según la pertenencia a un grupo de disciplinas de la ciencia. Para ello, se consideró la división clásica que establecen las universidades de la Argentina para

\footnotetext{
6 La muestra analizada se compone de los siguientes diarios digitales: Pregón (Jujuy), El Tribuno (Salta), La Gaceta (Tucumán), El Ancasti (Catamarca), El Liberal (Santiago del Estero), El Litoral (Corrientes), Norte (Chaco), La Mañana (Formosa), El Territorio (Misiones), La Voz del Interior (Córdoba), La Capital (Santa Fe), El Litoral (Santa Fe), La Arena (La Pampa), El Día (Buenos Aires), Clarín (CABA), La Nación (CABA), Página/12 (CABA), El Diario de la República (San Luis), Los Andes (Mendoza), El Diario de Cuyo (San Juan), El Independiente (La Rioja), Río Negro (Río Negro), Patagónico (Chubut), La Opinión Austral (Santa Cruz) y El Sureño (Tierra del Fuego). Cabe aclarar que se había seleccionado en el corpus de análisis El Diario (Entre Ríos), pero este medio dejó de funcionar durante el periodo de análisis declarándose en cesación de pago (tanto con sus empleados como con el servicio de hosting de la versión digital del periódico), por lo que debió excluirse de la muestra.

7 Por el sistema de medios nacional, las prácticas periodísticas suelen identificar a la primera franja de producción y publicación (entre las 6 y las 9 horas) con la última etapa de cierre general (las 19 horas), en correspondencia con los tiempos de las versiones impresas y los horarios de noticieros radiales y televisivos.
} 
Guillermo Damián Spina, Cecilia Beatriz Díaz

La cobertura de las noticias científicas en diarios digitales argentinos (2017-2018)

agrupar sus carreras en escuelas, facultades o departamentos. ${ }^{8}$ De tal manera, se estipularon las siguientes categorías: "Agrarias" "Arte y Arquitectura", "Económicas", "Exactas y Naturales", "Humanidades", "Ingenierías", "Salud" y la opción "interdisciplinaria" para los casos en que el ítem aborde un tema desde distintas disciplinas científicas.

Por su parte, la variable producción de la información (V07) registra el agente que produce el contenido del ítem informativo, por lo tanto, quien firma puede adquirir valor como "periodista" (redactor con firma), "redacción" (firma colectiva), "corresponsal" (periodista que contribuye con el medio desde una locación distante, nacional o extrajera, siempre y cuando aparezca identificado como tal), "agencia de noticias", "otro medio/divulgador" (se reproduce lo publicado por otro medio sin intervención del medio analizado o, en su defecto, es divulgador free lance) y "no se puede determinar" (cuando no hay ningún tipo de firma).

En el caso de la variable que determina el tipo de información (V08), indica el tratamiento dado a la noticia a partir del género periodístico utilizado. De esta forma, se establecen como categorías: "noticia" (el género más breve y clásico), "reportaje" (tratamiento de mayor extensión y tecnicismo), "entrevista" (se considera tanto el modo pregunta/respuesta como el glosado) e "informe" (reúne varios segmentos informativos de distinto tipo de género por la complejidad y profundidad del abordaje otorgado por el medio).

En cuanto a las variables vinculadas a las fuentes, categorizamos la naturaleza de la información (V22) en "documental" (cuando se basa en informes, publicaciones escritas y/o documentos oficiales), "humana" (en los casos en que se expresa una persona en nombre de una organización en calidad de vocero), “documental y humana” (si coexisten ambas opciones en el mismo ítem noticioso) y "no se puede determinar" (los casos en que el redactor de la información en su enunciado no dé cuenta de la naturaleza de la fuente utilizada).

Por otro lado, en la variable cantidad de fuentes (V23) se contabiliza el total de las distintas fuentes utilizadas en la noticia analizada. Luego, la variable tipo de fuente (V24) remite a los grupos de interés explicitados que suministran la información publicada. Esto implica que la variable admite múltiples opciones por cada ítem analizado. Se clasifican en las siguientes opciones: "Estado" (administración del Gobierno nacional, provincial o municipal, incluyendo los tres poderes del Estado y organismos autónomos de la República Argentina), "empresa" (toda fuente del ámbito privado empresarial nacional), "sociedad civil" (representantes de sociedades civiles organizadas), "internacional" (orga-

\footnotetext{
8 Esta decisión de adoptar el criterio de la división disciplinar argentina se fundamenta en la correspondencia con el origen del corpus de prensa analizado. Esto contribuye a la categorización de los ítems noticiosos a partir de la nomenclatura de los campos disciplinares que determinan los planes de estudio y las especialidades de los institutos de investigación y laboratorios donde se produce y acredita el conocimiento científico.

9 En la categoría Humanidades se contempla el estudio de las especialidades de las Ciencias Sociales.
} 
nizaciones u organismos extranjeros), "experto" (se cita a un investigador en el tema) y "no se puede determinar" (cuando esa información es omitida).

Finalmente, la variable procedencia de la fuente (V25) permite subclasificar a las fuentes con un mayor grado de precisión en cuanto a su posición geográfica en las siguientes categorías: "universidad nacional argentina", "universidad privada de la argentina", "laboratorio/instituto argentino" (todo laboratorio o instituto perteneciente al ámbito privado), "Gobierno nacional/provincial/municipal" (representa a fuentes provenientes del Estado tanto del ámbito nacional y provincial como municipal, incluyendo laboratorios e institutos dependientes directamente de dichos gobiernos), "universidad extranjera", "laboratorio/instituto extranjero" (laboratorios y/o institutos privados extranjeros), "Gobierno extranjero/institución extranjera" (fuentes de Gobiernos extranjeros, incluyendo institutos de dependencia gubernamental de otros países), "investigador independiente" (investigadores nombrados por su incumbencia específica y no por su dependencia institucional), "publicación específica" (publicaciones del campo de la comunicación científica que sean tomadas como fuente) y "no se puede determinar". Dado que cada ítem noticioso puede presentar varias fuentes de información, esta variable admite múltiples opciones.

Estas variables para contabilizar y analizar las fuentes utilizadas en ítems noticiosos de temáticas científicas tienen como finalidad caracterizar el nivel de participación de diferentes agentes sociales en el campo del periodismo científico.

\section{Resultados}

En la muestra anual relevada durante el periodo analizado, se identificaron 619 casos de ítems sobre temática científica distribuidos en los veinticinco diarios digitales argentinos analizados, repartidos en las mil cincuenta capturas de pantallas relevadas correspondientes a las catorce fechas en que se configuraron las dos semanas construidas y en las tres frecuencias horarias captadas en cada caso, los cuales conformaron el corpus de análisis correspondiente a la muestra.

\section{a) Temática científica}

Los resultados evidencian que las especialidades más publicadas en los diarios digitales argentinos son Salud (28,4\%), Económicas (21,8\%), Exactas y Naturales $(20,2 \%)$, Humanidades (9,9\%), interdisciplinarias (8,9\%), Agrarias e Ingenierías (5\% cada una) y Artes y Arquitectura (0,8\%).

\footnotetext{
${ }^{10}$ En esta categoría se agrupan las fuentes que provienen de universidades no argentinas. Se ha decidido no realizar una subdivisión entre la gestión privada o pública en esta dimensión debido a que según las normativas de cada país, las concepciones sobre la administración universitaria varían significativamente.
} 
Guillermo Damián Spina, Cecilia Beatriz Díaz

La cobertura de las noticias científicas en diarios digitales argentinos (2017-2018)

Tabla 1. Temáticas científicas (V09) ${ }^{11}$

\begin{tabular}{|c|c|c|c|c|}
\hline \multicolumn{2}{|c|}{ Temáticas científicas } & Frecuencia & $\%$ & $\%$ acumulado \\
\hline \multirow{9}{*}{$\frac{\text { 은 }}{\text { 穷 }}$} & Agrarias & 31 & 5 & 5 \\
\hline & Artes y Arquitectura & 5 & 0,8 & 5,8 \\
\hline & Económicas & 135 & 21,8 & 27,6 \\
\hline & Exactas y Naturales & 125 & 20,2 & 47,8 \\
\hline & Humanidades & 61 & 9,9 & 57,7 \\
\hline & Ingenierías & 31 & 5 & 62,7 \\
\hline & Salud & 176 & 28,4 & 91,1 \\
\hline & Interdisciplinarias & 55 & 8,9 & 100 \\
\hline & Total & 619 & 100 & \\
\hline
\end{tabular}

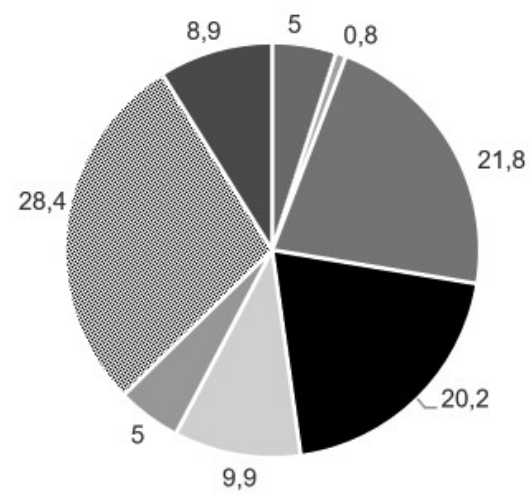

$\begin{array}{lll}\text { - Agrarias } & \text { " Artes y Arquitectura } & \text { - Económicas } \\ \text { - Exactas y Naturales } & \text { " Humanidades } \\ \text { * Salud } & \text { - Interdisciplinarias }\end{array}$

Figura 1. Temáticas científicas (V09).

A continuación, exponemos los resultados del relevamiento en las variables vinculadas a la producción noticiosa y al uso de fuentes.

${ }^{11}$ Todas las fuentes y figuras son de elaboración propia. 
Austral Cmunicación

Volumen 9, número 1 (Junio de 2020): 5-43. ISSN 2313-9129

\section{b) Producción de la información}

Esta variable permite observar cuál es el agente responsable de la producción de los ítems noticiosos sobre ciencia en los diarios argentinos analizados. En el periodo relevado, se observó que en el 51,5\% de los ítems noticiosos no se pudo determinar quién escribió el artículo, encontrando que solo el 18,1\% fueron firmados por un periodista, mientras que el 10,7\% de la muestra fue atribuido a la "redacción" del medio. En una frecuencia inferior, las noticias fueron producidas por agencia de noticias $(9,8 \%)$, otro medio y/o divulgador $(8,9 \%)$ y corresponsal (1\%).

Tabla 2. Producción de la información (V07)

\begin{tabular}{|c|c|c|c|c|}
\hline \multicolumn{2}{|c|}{ Producción de la información } & \multirow{2}{*}{$\begin{array}{c}\text { Frecuencia } \\
112\end{array}$} & \multirow{2}{*}{$\begin{array}{l}\% \\
18,1\end{array}$} & \multirow{2}{*}{$\begin{array}{c}\text { \% acumulado } \\
18,1\end{array}$} \\
\hline \multirow{7}{*}{ 을 } & Periodista & & & \\
\hline & Redacción & 66 & 10,7 & 28,8 \\
\hline & Corresponsal & 6 & 1 & 29,7 \\
\hline & Agencia de noticias & 61 & 9,8 & 39,6 \\
\hline & Otro medio/divulgador & 55 & 8,9 & 48,5 \\
\hline & No se puede determinar & 319 & 51,5 & 100 \\
\hline & Total & 619 & 100 & \\
\hline
\end{tabular}

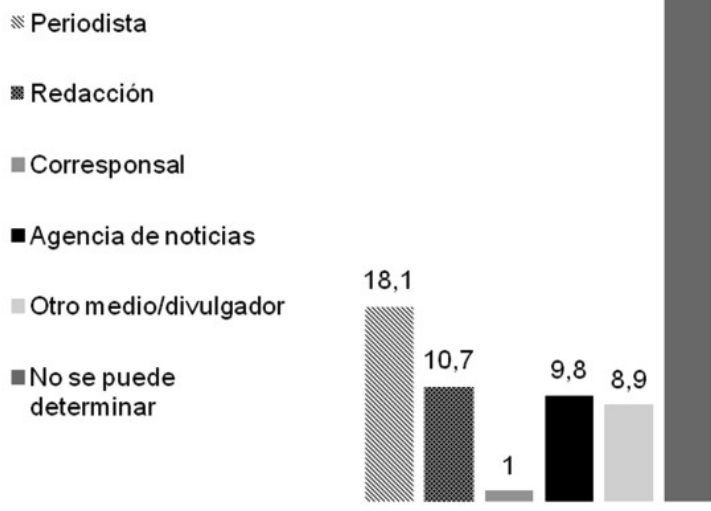

Figura 2. Producción de la información (V07). 
Guillermo Damián Spina, Cecilia Beatriz Díaz

La cobertura de las noticias científicas en diarios digitales argentinos (2017-2018)

En particular, en Agrarias se observa que en su mayoría no puede determinarse la autoría de los ítems noticiosos (54,8\%), mientras que el 19,4\% menciona a la redacción y el $16,1 \%$ presenta la firma de un periodista.

En Arte y Arquitectura hay una mayor paridad entre los ítems sin firma (40\%) y los que identifican a un periodista como autor (40\%). Detrás se encuentra el recurso del corresponsal (20\%), que presentó una frecuencia superior al total de la muestra nacional.

En las temáticas vinculadas a Económicas se observa un predominio de la falta de explicitación de la autoría de los ítems analizados (56,3\%), aunque hay una mayor proporción de los tipos de producción de la información, los cuales se distribuyen de la siguiente manera: el 13,3\% corresponde a periodistas y agencias de noticias; el 12,6\%, a la redacción; y el 4,4\%, a divulgador u otro medio.

Un comportamiento similar se observa en las noticias de Exactas y Naturales, en tanto que el $63,2 \%$ no se puede determinar, el $12 \%$ corresponde a las agencias de noticias; el 9,6\%, a periodistas; y el 7,2\%, tanto a redacción como a otros medios.

En las noticias de Humanidades, en el 39,3\% de los ítems no se pudo determinar la autoría de la producción de la información, mientras que el 32,8\% corresponde a un periodista; el $14,8 \%$, a otro medio o divulgador; un $8,2 \%$, a la redacción del medio; y un 4,9 , a la agencia de noticias.

En cuanto a Ingenierías, se destaca el mayor número de ítems producidos por otro medio o divulgador (16,1\%). Si bien se sostiene que la mayoría de las noticias se registran sin firma, tanto la categoría de periodistas como la de agencia de noticias alcanzan el 12,9\%; y la redacción y la corresponsalía, el 3,2\% cada una.

Por otra parte, las noticias vinculadas a Salud presentan algunas diferencias con los resultados totales de la muestra: el 46,6\% no cuenta con identificación de autoría, el $22,2 \%$ son firmadas por un periodista; el 12,5\%, por la redacción, el 11,9\% corresponde a una reproducción de otro medio o divulgador; y el 6,8\%, a una agencia de noticias.

En cuanto al comportamiento de las noticias de temática interdisciplinaria, se observa una mayor paridad en la responsabilidad de la producción de la información, aunque lidera la práctica de no firmar los ítems (42,6\%). De ese modo, un 20,4\% le adjudica la autoría a un periodista en particular; el 13\%, a las agencias de noticias; el $11,1 \%$, a la redacción; el 7,4\%, a otro medio o divulgador; y el 5,6\% a los corresponsales. 
Austral Comunicación

Volumen 9, número 1 (Junio de 2020): 5-43. ISSN 2313-9129

Tabla 2.1. Producción de la información (V07) según temática científica (V9)

\begin{tabular}{|c|c|c|c|c|c|c|c|c|c|}
\hline \multicolumn{2}{|c|}{ Producción de la información } & Agrarias & $\begin{array}{l}\text { Arte y } \\
\text { Arquitectura }\end{array}$ & Económicas & $\begin{array}{l}\text { Exactasy } \\
\text { Naturales }\end{array}$ & Humanidades & Ingenierías & Salud & Interdisciplinarias \\
\hline \multirow{7}{*}{$\frac{\text { 은 }}{\text { 穷 }}$} & Periodista & 16,1 & 40 & 13,3 & 9,6 & 32,8 & 12,9 & 22,2 & 20,4 \\
\hline & Redaccion & 19,4 & 0 & 12,6 & 7,2 & 8,2 & 3,2 & 12,5 & 11,1 \\
\hline & Corresponsal & 0,0 & 20 & 0,0 & 0,8 & 0,0 & 3,2 & 0,0 & 5,6 \\
\hline & Agencia de noticias & 6,5 & 0 & 13,3 & 12,0 & 4,9 & 12,9 & 6,8 & 13,0 \\
\hline & Otro medio/divulgador & 3,2 & 0 & 4,4 & 7,2 & 14,8 & 16,1 & 11,9 & 7,4 \\
\hline & No se puede determinar & 54,8 & 40 & 56,3 & 63,2 & 39,3 & 51,6 & 46,6 & 42,6 \\
\hline & Total & 100 & 100 & 100 & 100 & 100 & 100 & 100 & 100 \\
\hline
\end{tabular}

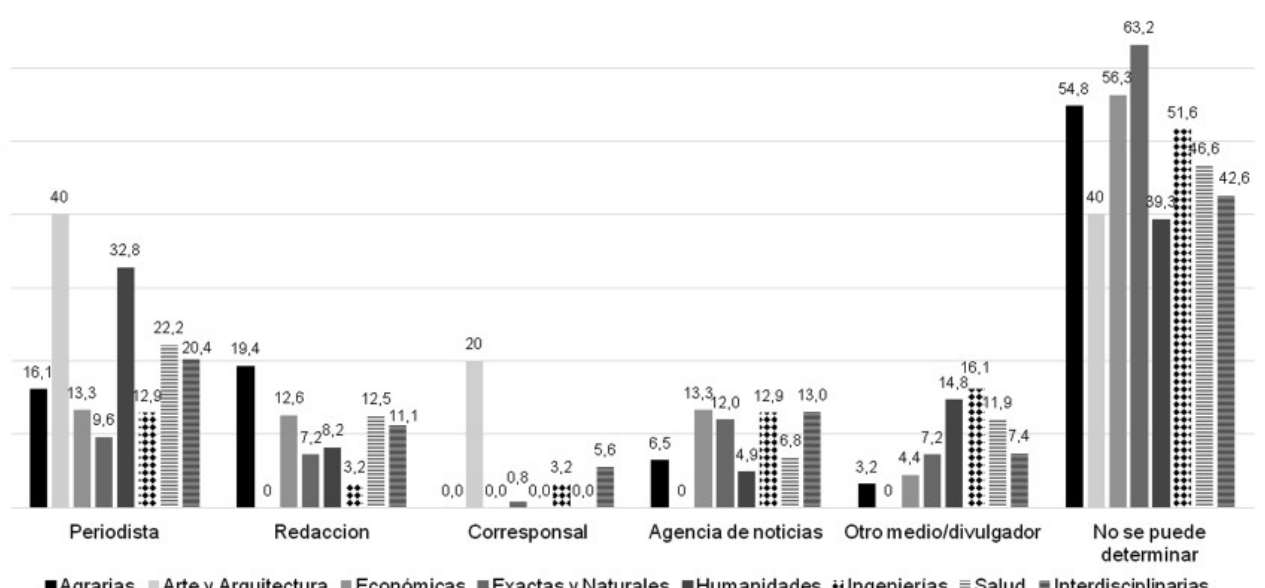

-Agrarias $\approx$ Arte y Arquitectura $=$ Economicas $=$ Exactas y Naturales $=$ Humanidades

Figura 2.1. Producción de la información (V07) según temática científica (V9).

Es interesante destacar que la corresponsalía no fue utilizada por las disciplinas Agrarias, Económicas, Humanidades y de Salud, lo cual puede comprenderse por su presencia cercana en los territorios que no exige un cronista enviado al lugar de los hechos.

\section{c) Tipo de información}

En cuanto al tipo de información que da cuenta del género periodístico elegido por las editoriales de los diarios digitales analizados, se observa que en la mayoría de 
Guillermo Damián Spina, Cecilia Beatriz Díaz

La cobertura de las noticias científicas en diarios digitales argentinos (2017-2018)

los casos se aborda la información científica mediante el género noticia (59,6\%) seguido de la opción reportaje (36\%); luego, en una frecuencia significativamente menor, se recurre a la entrevista $(2,4 \%)$ y, finalmente, al género informe $(2 \%)$, el cual requiere una mayor producción y espacio en el diario.

Tabla 3. Tipo de información (V08)

\begin{tabular}{|c|c|c|c|c|}
\hline \multicolumn{2}{|c|}{ Producción de la información } & \multirow{2}{*}{$\begin{array}{c}\text { Frecuencia } \\
369\end{array}$} & \multirow{2}{*}{$\begin{array}{l}\% \\
59,6\end{array}$} & \multirow{2}{*}{$\begin{array}{c}\% \text { acumulado } \\
59,6\end{array}$} \\
\hline \multirow{5}{*}{ 을 } & Noticia & & & \\
\hline & Reportaje & 223 & 36 & 95,6 \\
\hline & Entrevista & 15 & 2,4 & 98 \\
\hline & Informe & 12 & 2 & 100 \\
\hline & Total & 619 & 100 & \\
\hline
\end{tabular}

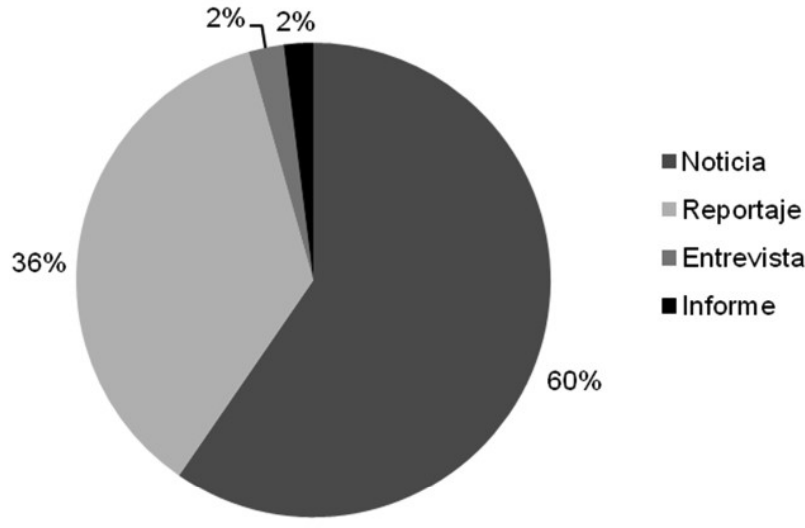

Figura 3. Tipo de información (V08).

Cuando observamos el comportamiento de esta variable en cada temática científica pueden encontrarse matices, ya sea en el orden como en la proporción de frecuencia en el uso de géneros para comunicar la ciencia. En lo relativo a Salud, el 48,3\% de los ítems relevados recurre al género del reportaje; mientras que el $47,7 \%$, a la noticia; el $2,3 \%$, al informe; y el 1,7\%, a la entrevista.

En los abordajes interdisciplinarios, la noticia acapara el 55,6\%; el reportaje, el $35,2 \%$; y el informe, el 9,3\%. 
Austral Cmunicación

Volumen 9, número 1 (Junio de 2020): 5-43. ISSN 2313-9129

Ingenierías y Exactas y Naturales comparten el mismo orden de ponderación y proporción de los géneros discursivos: noticia $(67,7 \%$ y $71,2 \%$, respectivamente), reportaje $(25,8 \%$ y $25,6 \%)$ y entrevista $(6,5 \%$ y $2,4 \%)$. En el caso Económicas, el $80 \%$ de su publicación se presenta en formato de noticia; el 19\%, en reportaje; y el 1\%, en entrevista.

Tabla 3.1. Tipo de información (V08) según temática científica (V9)

\begin{tabular}{|c|c|c|c|c|c|c|c|c|c|}
\hline \multicolumn{2}{|c|}{ Género periodístico } & Agrarias & $\begin{array}{l}\text { Arte y } \\
\text { Arquitectura }\end{array}$ & Económicas & $\begin{array}{l}\text { Exactasy } \\
\text { Naturales }\end{array}$ & Humanidades & Ingenierías & Salud & Interdisciplinarias \\
\hline \multirow{5}{*}{$\frac{\text { 음 }}{\frac{\pi}{3}}$} & Noticia & 45,2 & 40 & 80 & 71,2 & 32,8 & 67,7 & 47,7 & 55,6 \\
\hline & Reportaje & 51,6 & 60 & 19 & 25,6 & 55,7 & 25,8 & 48,3 & 35,2 \\
\hline & Entrevista & 0,0 & 0 & 1 & 2,4 & 9,8 & 6,5 & 1,7 & 0,0 \\
\hline & Informe & 3,2 & 0 & 0 & 0,8 & 1,6 & 0,0 & 2,3 & 9,3 \\
\hline & Total & 100 & 100 & 100 & 100 & 100 & 100 & 100 & 100 \\
\hline
\end{tabular}

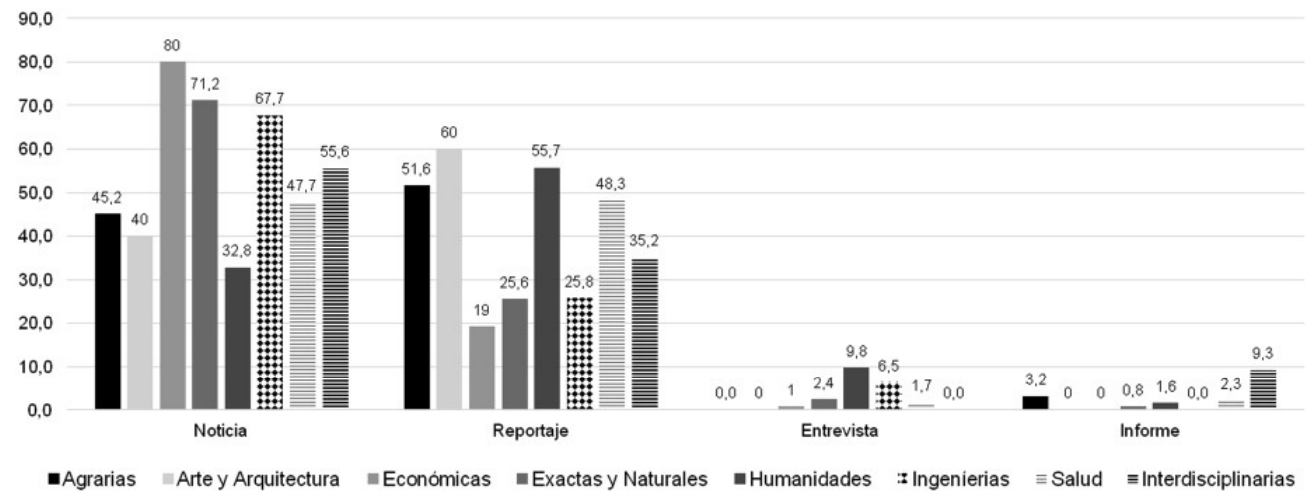

Figura 3.1. Tipo de información (V08) según temática científica (V9).

Es interesante destacar que el género de reportaje domina en Humanidades (55,7\%), Arte y Arquitectura (60\%) y Agrarias (51,6\%). En particular, las primeras aparecen publicadas en forma de noticia en un 32,8\%; en entrevista, en un 9,8\%; y en informe, en un 1,6\%. Por su parte, la noticia alcanza el $40 \%$ en los ítems noticiosos sobre Arte y Arquitectura. Similares valores alcanza Agrarias: $45,2 \%$ en formato de noticia y $3,2 \%$ en informe. 
Guillermo Damián Spina, Cecilia Beatriz Díaz

La cobertura de las noticias científicas en diarios digitales argentinos (2017-2018)

\section{d) Naturaleza de la fuente}

En cuanto al tratamiento de fuentes, en esta variable se contabilizaron los ítems de ciencia que contenían fuentes documentales humanas de manera particular o combinada. Al respecto, el estudio nos indica que el $35,4 \%$ de las noticias sobre ciencia en diarios digitales argentinos recurrió a la fuente documental, mientras que el 27,6\% citó documentos y a personas como origen del contenido; un $26 \%$ se basó en declaraciones de fuentes humanas y solo en el $11 \%$ este dato no se pudo determinar.

$\mathrm{Al}$ observar estas cifras, se puede inferir que la naturaleza documental es predominante en el uso de fuentes periodísticas sobre ciencia en los diarios digitales argentinos.

Tabla 4. Naturaleza de la fuente (V22)

\begin{tabular}{|c|c|c|c|c|}
\hline \multicolumn{2}{|c|}{ Naturaleza de la fuente } & \multirow{2}{*}{$\begin{array}{c}\text { Frecuencia } \\
219\end{array}$} & \multirow{2}{*}{$\begin{array}{l}\% \\
35,4\end{array}$} & \multirow{2}{*}{$\begin{array}{c}\text { \% acumulado } \\
35,4\end{array}$} \\
\hline \multirow{5}{*}{ 은 } & Fuente documental & & & \\
\hline & Fuente humana & 161 & 26 & 61,4 \\
\hline & Fuente documental y humana & 171 & 27,6 & 89 \\
\hline & No se puede determinar & 68 & 11 & 100 \\
\hline & Total & 619 & 100 & \\
\hline
\end{tabular}

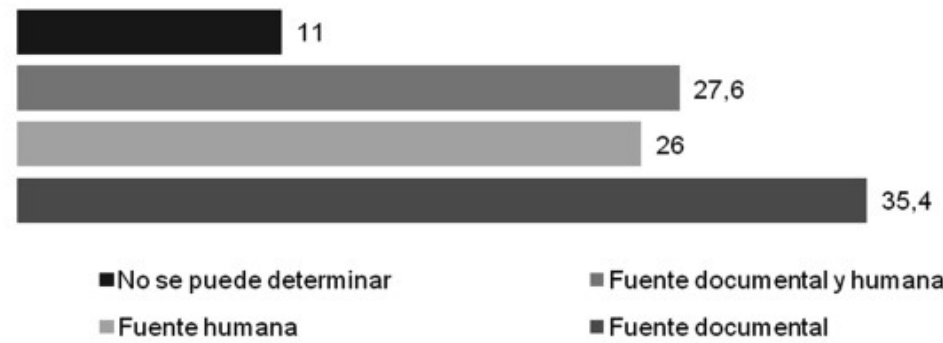

Figura 4. Naturaleza de la fuente (V22)

Pero al observar el comportamiento de la misma variable por temática científica vemos que presenta diferencias con el resultado total de la muestra. Las fuentes humanas predominan en Agrarias, Salud, Humanidades e Ingenierías por sobre las documentales. 
Austral Comunicación

Volumen 9, número 1 (Junio de 2020): 5-43. ISSN 2313-9129

Tabla 4.1. Naturaleza de la fuente (V22) según temática científica (V9)

\begin{tabular}{|c|c|c|c|c|c|c|c|c|c|}
\hline \multicolumn{2}{|c|}{ Género periodístico } & Agrarias & $\begin{array}{l}\text { Artey } \\
\text { Arquitectura }\end{array}$ & Económicas & $\begin{array}{l}\text { Exactasy } \\
\text { Naturales }\end{array}$ & Humanidades & Ingenierías & Salud & Interdisciplinarias \\
\hline \multirow{5}{*}{$\frac{\stackrel{8}{0}}{\frac{20}{3}}$} & Noticia & 45,2 & 40 & 80 & 71,2 & 32,8 & 67,7 & 47,7 & 55,6 \\
\hline & Reportaje & 51,6 & 60 & 19 & 25,6 & 55,7 & 25,8 & 48,3 & 35,2 \\
\hline & Entrevista & 0,0 & 0 & 1 & 2,4 & 9,8 & 6,5 & 1,7 & 0,0 \\
\hline & Informe & 3,2 & 0 & 0 & 0,8 & 1,6 & 0,0 & 2,3 & 9,3 \\
\hline & Total & 100 & 100 & 100 & 100 & 100 & 100 & 100 & 100 \\
\hline
\end{tabular}

En particular, predominan las fuentes humanas en Agrarias (41.9\%), Arte y Arquitectura (40\%), Salud (39,2\%), Ingenierías (38,7\%) y Humanidades $(36,1 \%)$; mientras que las fuentes documentales son más frecuentes en los ítems noticiosos de Económicas $(64,4 \%)$ y Exactas y Naturales (43,2\%). En las temáticas interdisciplinarias es posible encontrar el uso combinado de fuentes en un $44,4 \%$.

Por otra parte, el estudio arroja un dato interesante: la presencia significativa de ítems noticiosos con fuentes cuya naturaleza no se puede determinar. En este sentido, Agrarias muestra un 25,8\% de estos casos; Ingenierías, un 22,6\%; Arte y Arquitectura, un $20 \%$; Salud, un 13,6\%; y Exactas, un 11,2\%.

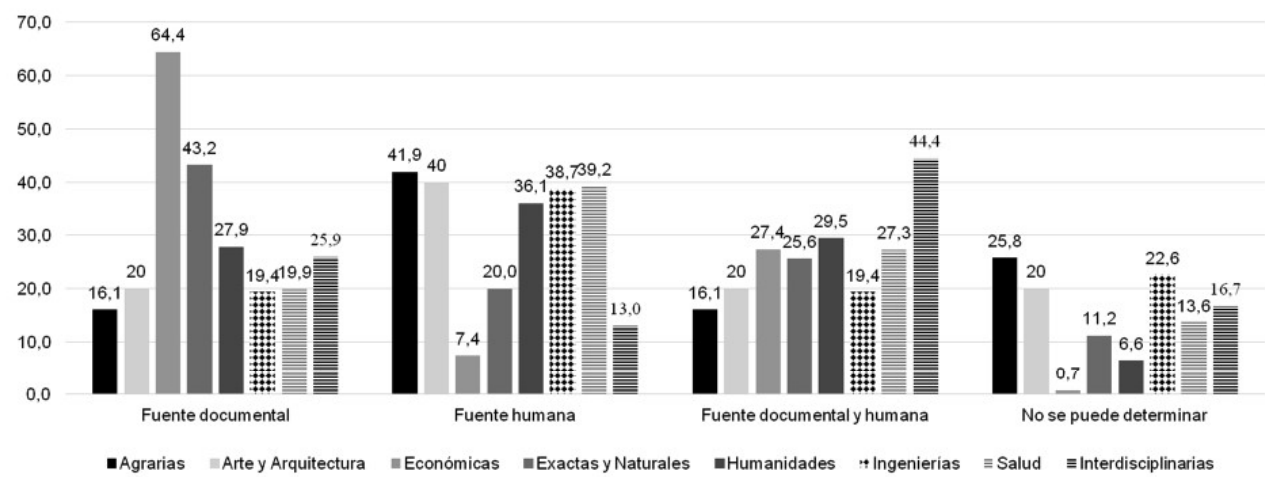

Figura 4.1. Naturaleza de la fuente (V22) según temática científica (V9).

\section{e) Cantidad de fuentes}

Otra dimensión del tratamiento periodístico fue contabilizar la cantidad de fuentes distintas en las notas sobre ciencia. Los datos de la muestra son elocuentes al res- 
Guillermo Damián Spina, Cecilia Beatriz Díaz

La cobertura de las noticias científicas en diarios digitales argentinos (2017-2018)

pecto: el 52,2\% citó una sola fuente; el 22,3\%, dos fuentes; el 10,8\%, tres fuentes; y las cifras muestras un comportamiento proporcional a un mayor número de fuentes, de manera que a medida que crece la cantidad de fuentes utilizadas, disminuyen los casos.

Tabla 5. Cantidad de fuentes (V23)

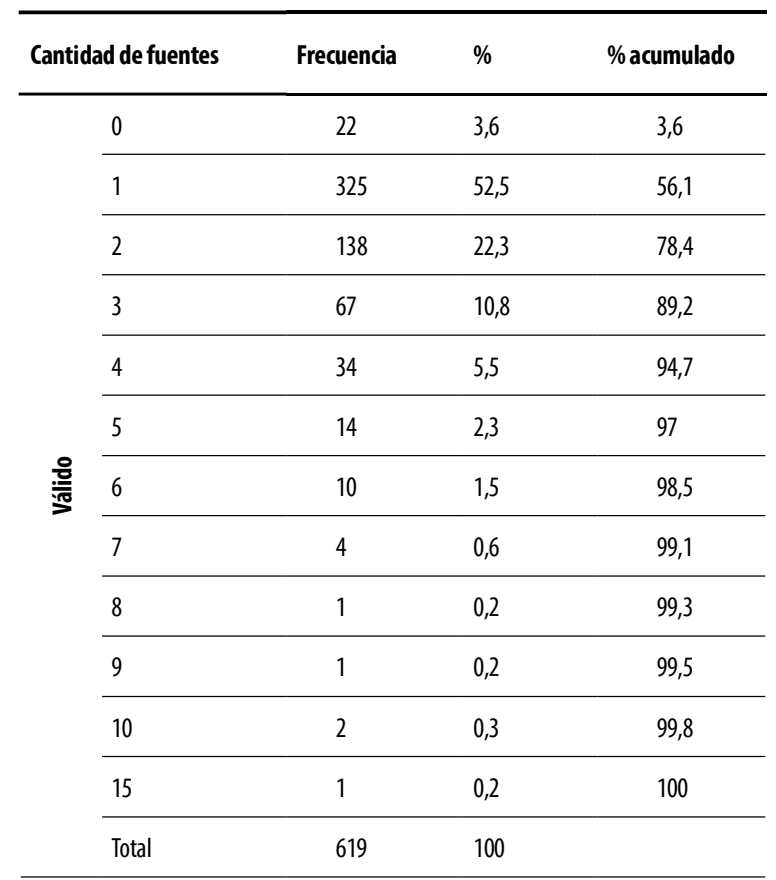

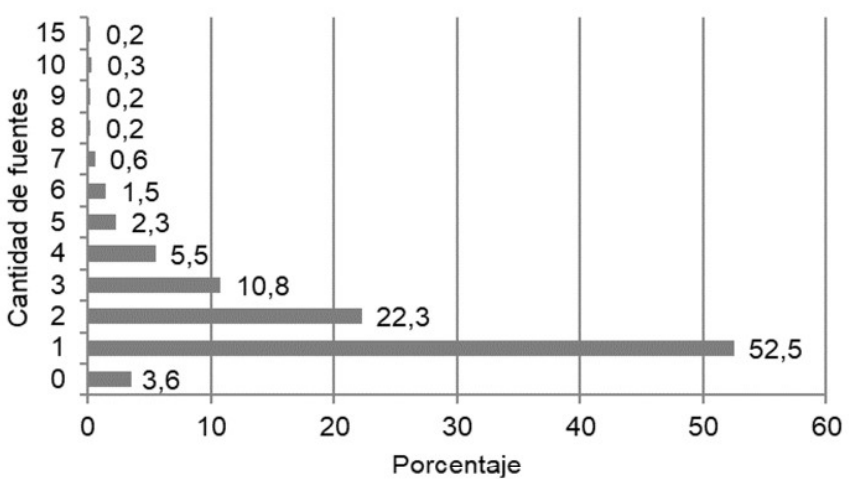

Figura 5. Cantidad de fuentes 
Cuando observamos el comportamiento de esta variable en el cruce con el tipo de temática científica, se evidencia que el orden de ponderación en cada disciplina no se altera. Es decir, la práctica de recurrir a una sola fuente es generalizada. Y si analizamos el comportamiento en cada agrupamiento, se evidencia que cuando aumenta el número de fuentes consultadas, se reducen los ítems publicados. Este dato permite inferir la falta de diversidad de fuentes informativas especializadas.

Tabla 5.1. Cantidad de fuentes (V23) según temática científica (V9)

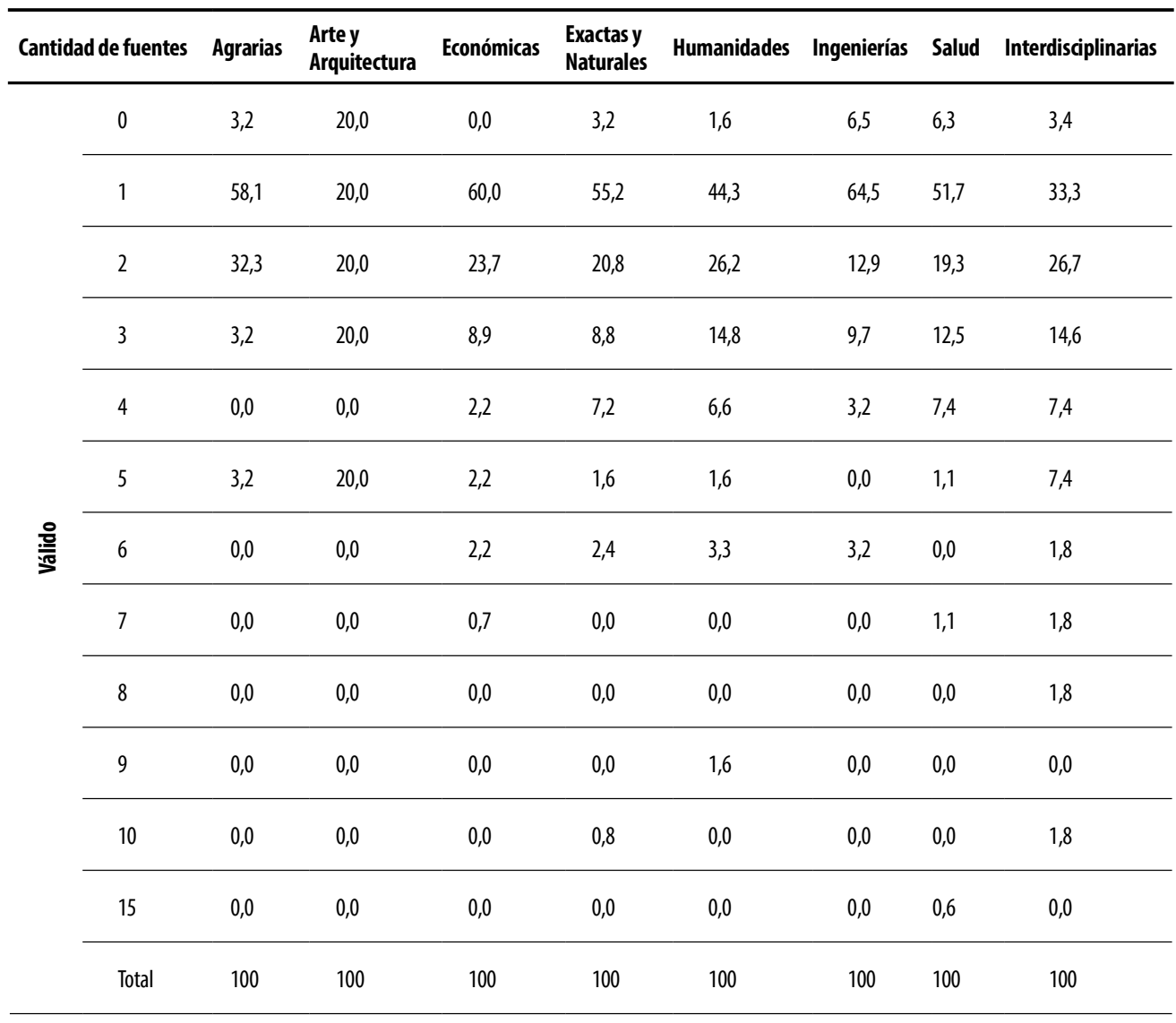


Guillermo Damián Spina, Cecilia Beatriz Díaz

La cobertura de las noticias científicas en diarios digitales argentinos (2017-2018)

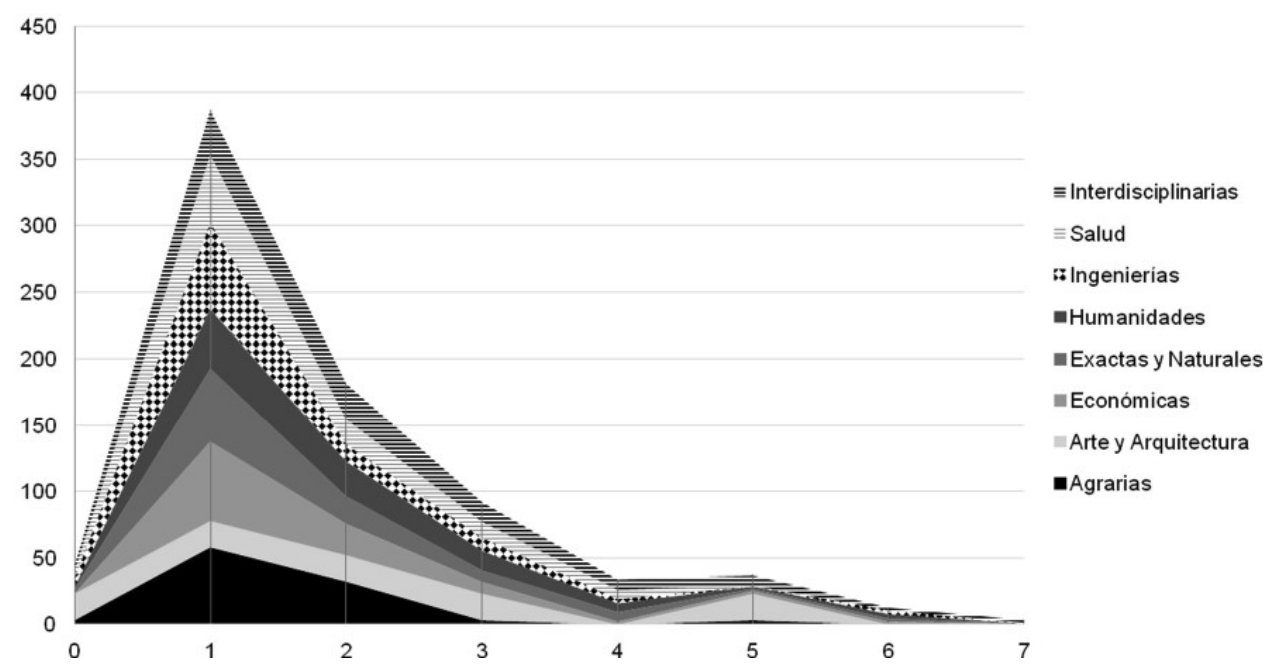

Figura 5.1. Cantidad de fuentes (V23) según temática científica (V9)

De manera específica, el uso de cierta cantidad de fuentes presenta matices de acuerdo con la temática científica. En las interdisciplinarias se observa una mayor distribución de ítems por cantidad de fuentes. En el 33,3\% de los casos se encontró una fuente; en el $26,7 \%$, dos fuentes; en el $12,5 \%$, tres fuentes; en el 7,4\%, cuatro y cinco fuentes. Incluso, esta temática es la única que muestra casos con diez citas (1,8\%).

En Agrarias, el 58,1\% de los ítems presenta una fuente; y el 32,3\%, solo dos; mientras que el 3,2\% cita cinco fuentes. Esta ponderación tiene su mayor margen en Económicas, donde el uso de una fuente asciende al 60\%; el uso de dos fuentes, al $23,7 \%$; y el uso de tres fuentes, al 8,9\%.

Un comportamiento similar se observa en Ingenierías, donde se pondera el uso de una fuente $(64,5 \%)$, de dos $(12,9 \%)$, de tres $(9,7 \%)$ y de ninguna $(6,5 \%)$, entre los valores más representativos.

En el resto de las temáticas científicas estudiadas se observa una correlación con la muestra general, en tanto que el uso de una única fuente predomina en Humanidades $(44,3 \%)$ y en Salud (51,7\%). A esto le siguen, respectivamente, dos fuentes $(26,2 \%$ y $19,3 \%)$, tres fuentes $(14,8 \%$ y $12,5 \%)$ y cuatro fuentes $(6,6 \%$ y $7,4 \%)$.

En Arte y Arquitectura no es posible observar una tendencia, dado que desde la falta de fuentes hasta la mención de cinco no supera el $20 \%$ cada una, por lo que no puede entenderse como una práctica dominante. 
Austral Comunicación

Volumen 9, número 1 (Junio de 2020): 5-43. ISSN 2313-9129

\section{f) Tipo de fuente}

En la variable sobre el tipo de fuente se relevó que, de los 619 ítems noticiosos, un $32,4 \%$ tiene como origen al Estado, mientras que el 25,1\% de los casos corresponde a fuentes de origen internacional; el $16 \%$ de la muestra representa a fuentes empresariales; el 13,6\%, a la figura del experto; y un 9,7\%, a la sociedad civil.

Tabla 6. Tipo de fuente (V24)

\begin{tabular}{|c|c|c|c|c|}
\hline \multicolumn{2}{|c|}{ Tipo de fuentes } & \multirow{2}{*}{$\begin{array}{c}\text { Frecuencia } \\
253\end{array}$} & \multirow{2}{*}{$\frac{\%}{32,4}$} & \multirow{2}{*}{$\begin{array}{c}\text { \% acumulado } \\
32,4\end{array}$} \\
\hline \multirow{6}{*}{$\frac{\text { 을 }}{\text { 䆑 }}$} & Estado & & & \\
\hline & Empresa & 125 & 16,0 & 48,4 \\
\hline & Sociedad civil & 76 & 9,7 & 58,1 \\
\hline & Internacional & 196 & 25,1 & 83,2 \\
\hline & Experto & 106 & 13,6 & 96,8 \\
\hline & $\begin{array}{l}\text { No se puede } \\
\text { determinar }\end{array}$ & 25 & 3,2 & 100,0 \\
\hline
\end{tabular}

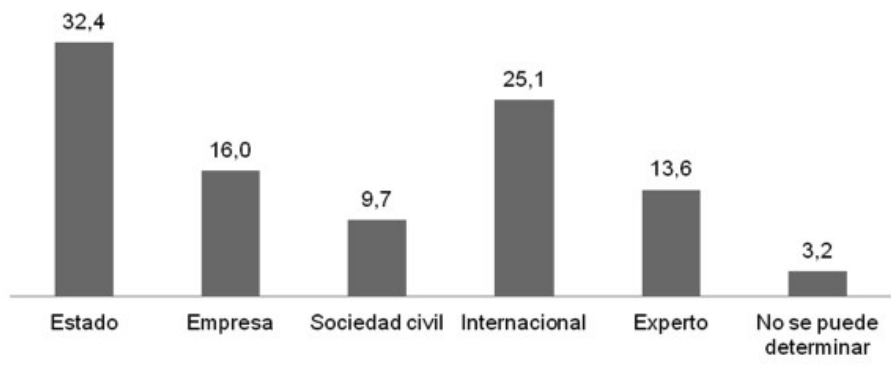

Figura 6. Tipo de fuente (V24).

Al desagregar la variable "tipo de fuente" según la temática científica publicada por los diarios digitales analizados, la disciplina científica abordada que presenta una mayor pluralidad de tipo de fuentes es la vinculada a Salud.

Un escenario distinto al de la media de la muestra lo constituye el caso de Económicas. Incluso es en el único caso en el que el tipo de fuente empresarial (40,6\%) supera al del tipo estatal $(34,7 \%)$. A su vez, en esta misma temática se identifica la mayor cantidad de casos de fuentes correspondientes a la sociedad civil (17,1\%). 
Guillermo Damián Spina, Cecilia Beatriz Díaz

La cobertura de las noticias científicas en diarios digitales argentinos (2017-2018)

Tabla 6.1. Tipo de fuente (V24) según temática científica (V9)

\begin{tabular}{|c|c|c|c|c|c|c|c|c|c|}
\hline \multicolumn{2}{|c|}{ Tipo de fuentes } & \multirow{2}{*}{$\begin{array}{c}\text { Agrarias } \\
47,4\end{array}$} & \multirow{2}{*}{$\begin{array}{l}\begin{array}{l}\text { Arte y } \\
\text { Arquitectura }\end{array} \\
13\end{array}$} & \multirow{2}{*}{$\begin{array}{c}\text { Económicas } \\
34,7\end{array}$} & \multirow{2}{*}{$\begin{array}{c}\begin{array}{c}\text { Exactas y } \\
\text { Naturales }\end{array} \\
41,1\end{array}$} & \multirow{2}{*}{$\begin{array}{c}\text { Humanidades } \\
33,8\end{array}$} & \multirow{2}{*}{ Ingenierías } & \multirow{2}{*}{$\begin{array}{l}\text { Salud } \\
26,7\end{array}$} & \multirow{2}{*}{$\begin{array}{c}\text { Interdisciplinarias } \\
26,6\end{array}$} \\
\hline & Estado & & & & & & & & \\
\hline & Empresa & 23,7 & 13 & 40,6 & 4,1 & 7,8 & 18,4 & 8,4 & 10,1 \\
\hline & Sociedad Civil & 5,3 & 0 & 17,1 & 4,8 & 7,8 & 0,0 & 12,0 & 6,3 \\
\hline \multirow{4}{*}{ 을 } & Internacional & 10,5 & 37,5 & 2,4 & 37,7 & 23,4 & 34,2 & 29,3 & 41,8 \\
\hline & Experto & 10,5 & 25 & 5,3 & 9,6 & 26,0 & 21,1 & 18,2 & 10,1 \\
\hline & $\begin{array}{l}\text { No se puede } \\
\text { determinar }\end{array}$ & 2,6 & 12,5 & 0,0 & 2,7 & 1,3 & 5,3 & 5,3 & 5,1 \\
\hline & Total & 100 & 100 & 100 & 100 & 100 & 100 & 100 & 100 \\
\hline
\end{tabular}

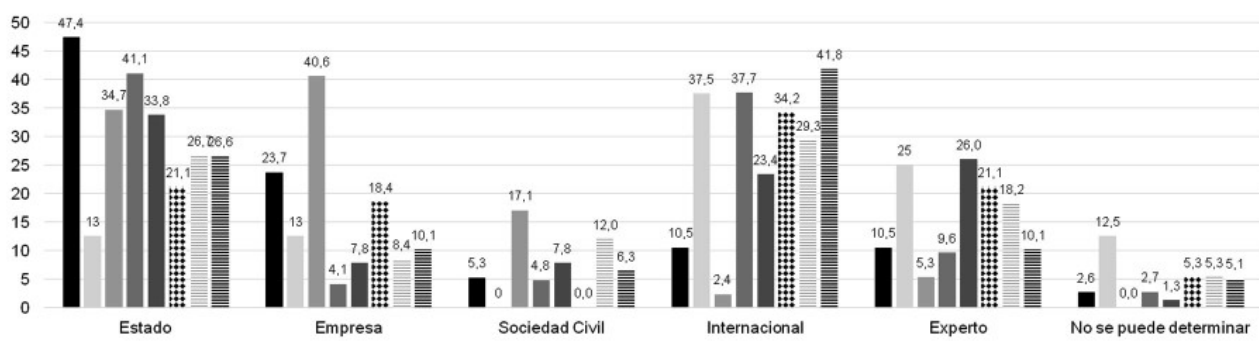

Figura 6.1. Tipo de fuente (V24) según temática científica (V9).

El "Estado" como tipo de fuente alcanza el 47,4\% en Agrarias, el 41,1\% en Exactas y Naturales, el 34,7\% en Económicas, el 33,8\% en Humanidades, el 26,7\% en Salud, el $26,6 \%$ en interdisciplinarias, el $21 \%$ en Ingenierías y el $13 \%$ en Arte y Arquitectura. Por su parte, la categoría "empresa", tal como lo adelantamos, predomina en Económicas y alcanza el 23,7\% de los ítems en Agrarias.

Respecto a la "sociedad civil" como tipo de fuente, se puede observar que si bien no es dominante, tiene una presencia significativa en la mayoría de las temáticas científicas: Económicas (17,1\%), Salud (12\%), Humanidades (7,8\%), Agrarias $(5,3 \%)$ y Exactas y Naturales $(4,8 \%)$.

Respecto a la categoría "internacional", se vuelve más recurrente en Exactas y Naturales (37,7\%), Arte y Arquitectura (37,5\%), Ingenierías (34,2\%), Salud (29,3\%) y Humanidades $(23,4 \%)$. Por su parte, la categoría "experto" es más utilizada en Humanidades (26\%), Arte y Arquitectura (25\%), Ingenierías $(21,1 \%)$ y Salud (18,2\%). 
Austral Comunicación

Volumen 9, número 1 (Junio de 2020): 5-43. ISSN 2313-9129

\section{g) Procedencia de la fuente}

En esta variable se clasifica la procedencia de la fuente para distinguir centros educativos y de investigación de agencias gubernamentales nacionales o extranjeras, lo que permite inferir el tipo de vínculo entre estas fuentes y los periodistas de los medios masivos de comunicación.

En nuestro relevamiento se observó una mayoría de fuentes nacionales, en la que predominó lo gubernamental (24,5\%), luego los laboratorios y/o institutos argentinos (19\%) y, más alejadas, las universidades nacionales (5,5\%). En cuanto a las fuentes foráneas, se evidenció un comportamiento similar y parejo: Gobierno extranjero $(9,5 \%)$, laboratorio extranjero (8\%) y universidad extranjera $(7,4 \%)$. Menor participación obtuvieron las procedencias más directas del sistema científico, como los investigadores independientes $(11,3 \%)$ y publicaciones específicas (8\%).

Tabla 7. Procedencia de la fuente (V25)

\begin{tabular}{lccc}
\hline Procedencia de la fuente & Frecuencia & $\%$ & \% acumulado \\
\hline Universidad nacional argentina & 47 & 5,5 & 5,5 \\
\hline Universidad privada argentina & 8 & 0,9 & 6,4 \\
\hline Laboratorio/instituto argentino & 164 & 19,0 & 25,4 \\
\hline Gobierno nacional/provincial/municipal & 211 & 24,5 & 49,9 \\
\hline Universidad extranjera & 64 & 7,4 & 57,3 \\
\hline Laboratorio/instituto extranjero & 69 & 8,0 & 65,3 \\
\hline Gobierno extranjero/institución extranjera & 82 & 9,5 & 74,8 \\
\hline $\begin{array}{l}\text { Total } \\
\text { Investigador independiente }\end{array}$ & 97 & 11,3 & 86,1 \\
\hline $\begin{array}{l}\text { Publicación específica } \\
\text { No se puede determinar }\end{array}$ & 69 & 8,0 & 94,1 \\
\hline
\end{tabular}


Guillermo Damián Spina, Cecilia Beatriz Díaz

La cobertura de las noticias científicas en diarios digitales argentinos (2017-2018)

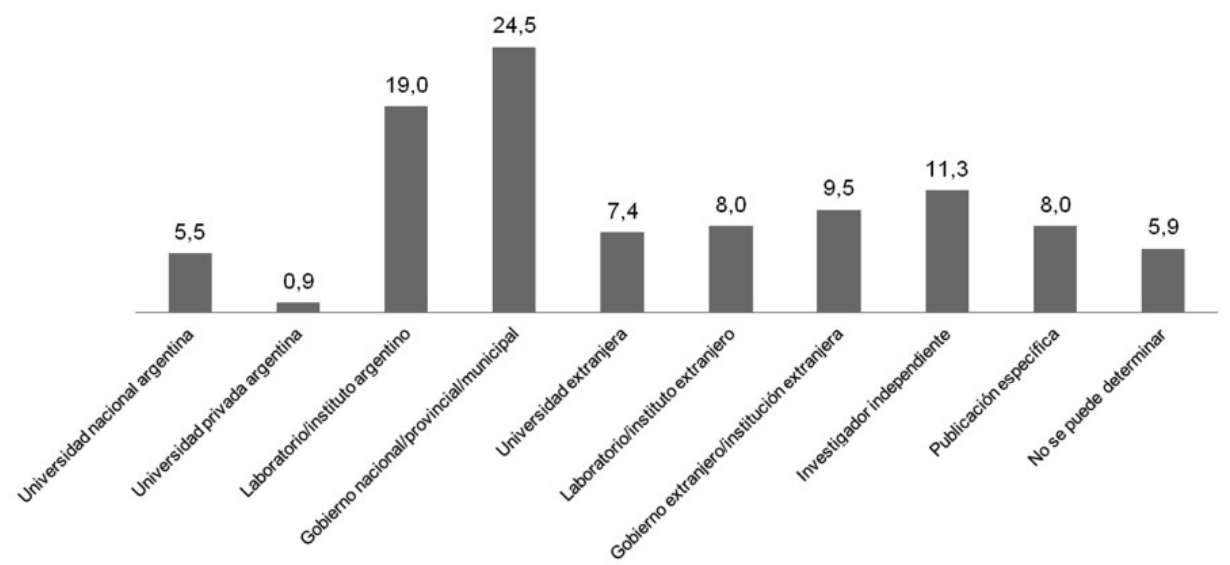

Figura 7. Procedencia de la fuente (V25).

En el caso de la "procedencia de la fuente", al analizar su conducta según las temáticas científicas abordadas por los ítems noticiosos que componen el corpus de análisis, encontramos que Salud es la que presenta una mayor pluralidad.

Dentro de los casos particulares, se destaca que Económicas utiliza más fuentes provenientes de laboratorios e institutos privados argentinos (49,7\%), y si bien en general las universidades privadas argentinas son poco utilizadas como fuentes, en la mayoría de los casos son fuentes de dichas temáticas económicas (2,9\%).

Otro dato llamativo es que tanto las universidades nacionales argentinas como las universidades extranjeras mayormente son fuentes de disciplinas de Exactas y Naturales (8,5\% y $11,9 \%$, respectivamente) como así también de Salud (4,2\% y 8,3\%, respectivamente). 
Austral Comunicación

Volumen 9, número 1 (Junio de 2020): 5-43. ISSN 2313-9129

Tabla 7.1. Procedencia de la fuente (V25) según temática científica (V9)

\begin{tabular}{|c|c|c|c|c|c|c|c|c|c|}
\hline \multicolumn{2}{|c|}{$\begin{array}{l}\text { Procedencia de } \\
\text { la fuente }\end{array}$} & Agrarias & $\begin{array}{l}\text { Arte y } \\
\text { Arquitectura }\end{array}$ & Económicas & $\begin{array}{l}\text { Exactas y } \\
\text { Naturales }\end{array}$ & Humanidades & Ingenierías & Salud & Interdisciplinarias \\
\hline \multirow{7}{*}{$\frac{\text { 은 }}{\text { 穷 }}$} & $\begin{array}{l}\text { Universidad } \\
\text { nacional } \\
\text { argentina }\end{array}$ & 7,5 & 0,0 & 1,7 & 8,5 & 4,7 & 7,5 & 4,2 & 9,3 \\
\hline & $\begin{array}{l}\text { Universidad } \\
\text { privada } \\
\text { argentina }\end{array}$ & 0,0 & 0,0 & 2,9 & 0,0 & 2,4 & 0,0 & 0,4 & 0,0 \\
\hline & $\begin{array}{l}\text { Laboratorio/ } \\
\text { instituto } \\
\text { argentino }\end{array}$ & 32,5 & 0,0 & 49,7 & 6,3 & 7,1 & 10,0 & 14,6 & 8,2 \\
\hline & $\begin{array}{l}\text { Gobierno } \\
\text { nacional/ } \\
\text { provincial/ } \\
\text { municipal }\end{array}$ & 35,0 & 22,2 & 30,9 & 25,6 & 28,2 & 15,0 & 20,8 & 16,5 \\
\hline & $\begin{array}{l}\text { Universidad } \\
\text { extranjera }\end{array}$ & 2,5 & 11,1 & 0,0 & 11,9 & 9,4 & 2,5 & 8,3 & 12,4 \\
\hline & $\begin{array}{l}\text { Laboratorio/ } \\
\text { instituto } \\
\text { extranjero }\end{array}$ & 0,0 & 11,1 & 0,6 & 9,1 & 10,6 & 20,0 & 9,6 & 11,3 \\
\hline & $\begin{array}{l}\text { Gobierno } \\
\text { extranjero/ } \\
\text { institución } \\
\text { extranjera }\end{array}$ & 7,5 & 0,0 & 2,3 & 15,9 & 4,7 & 12,5 & 10,8 & 12,4 \\
\hline & $\begin{array}{l}\text { Investigador } \\
\text { independiente }\end{array}$ & 5,0 & 22,2 & 3,4 & 8,0 & 23,5 & 17,5 & 16,3 & 7,2 \\
\hline & $\begin{array}{l}\text { Publicación } \\
\text { específica }\end{array}$ & 5,0 & 22,2 & 4,0 & 10,2 & 5,9 & 5,0 & 8,3 & 13,4 \\
\hline & $\begin{array}{l}\text { No se puede } \\
\text { determinar }\end{array}$ & 5,0 & 11,1 & 4,6 & 4,5 & 3,5 & 10,0 & 6,7 & 9,3 \\
\hline & Total & 100 & 100 & 100 & 100 & 100 & 100 & 100 & 100 \\
\hline
\end{tabular}


Guillermo Damián Spina, Cecilia Beatriz Díaz

La cobertura de las noticias científicas en diarios digitales argentinos (2017-2018)

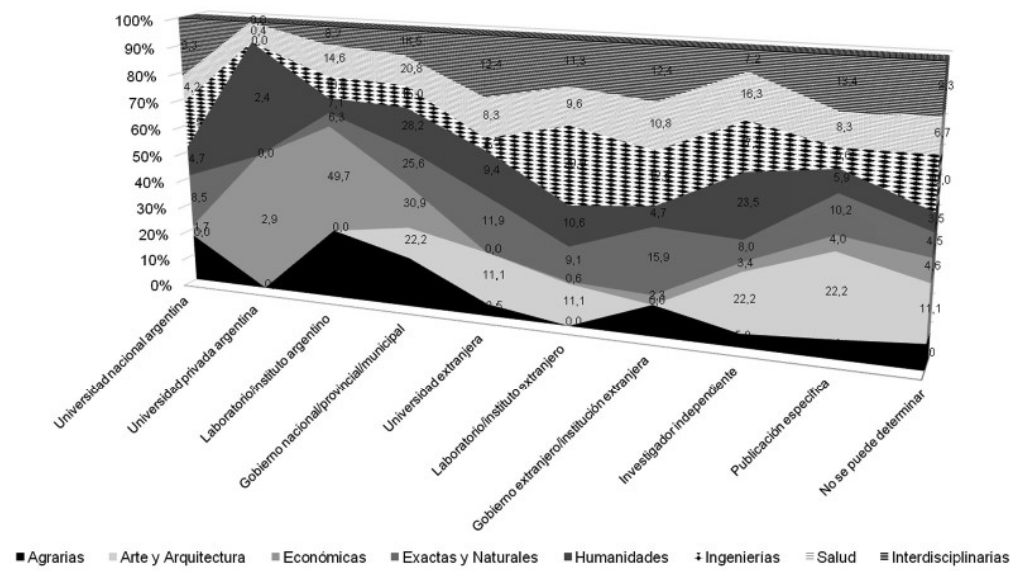

Figura 7.1. Procedencia de la fuente (V25) según temática científica (V9).

En síntesis, para el abordaje de Agrarias, los diarios digitales argentinos recurren al Gobierno nacional/provincial/local (35\%), a laboratorios e institutos argentinos $(32,5 \%)$, a la universidad nacional $(7,5 \%)$ y a Gobiernos e instituciones extranjeras (7,5\%). En Arte y Arquitectura, las fuentes más utilizadas son el Gobierno nacional/ provincial/local (22.2\%), investigadores independientes $(2,2 \%)$ y publicación específica $(22,2 \%)$, entre otras.

En Exactas y Naturales, el Gobierno nacional/provincial/local lidera con un 25,6\% como fuente más utilizada y le siguen Gobiernos extranjeros (15,9\%), universidad extranjera (11,9\%), publicación específica $(10,2 \%)$ y universidades nacionales $(8,5 \%)$.

Por su parte, Humanidades presenta una mayor pluralidad de procedencias de fuentes. Entre las más utilizadas encontramos el Gobierno nacional (28,2\%), investigador independiente $(23,5 \%)$, institutos extranjeros $(10,6 \%)$ y universidad extranjera $(9,4 \%)$, entre otras.

En cuanto a la cobertura de temáticas vinculadas a Ingenierías, las fuentes proceden de laboratorios/institutos extranjeros (20\%), investigador independiente (17,5\%), Gobiernos locales (15\%) y Gobiernos extranjeros (12,5\%), entre las más frecuentes.

Por último, las temáticas interdisciplinarias son abordadas por el periodismo argentino principalmente gracias a las fuentes que proceden del Gobierno nacional $(16,5 \%)$, publicación específica $(13,4 \%)$, universidad extranjera $(12,4 \%)$, Gobierno extranjero $(12,4 \%)$ y universidad nacional $(9,3 \%)$. 
Austral Comunicación

Volumen 9, número 1 (Junio de 2020): 5-43. ISSN 2313-9129

\section{Conclusiones}

El relevamiento de los ítems noticiosos sobre ciencia publicados en los diarios generalistas digitales argentinos durante el periodo analizado evidencia que la CPC no es valorada en su nivel de despliegue informativo, aunque presenta matices de acuerdo con las temáticas científicas tratadas.

En la muestra anual, los indicadores de producción periodística, tales como el tipo de producción, el género utilizado y el tratamiento de fuentes, demuestran que hay poca pluralidad y elaboración por parte de la prensa gráfica online.

Asimismo, el estudio da cuenta de que, en la mayoría de los casos, las publicaciones no identifican la producción. Este dato, junto con la escasez de fuentes utilizadas, permiten inferir que el tratamiento sobre las temáticas científicas no implica para el medio una valoración que le corresponda el reconocimiento de la autoría. ${ }^{12}$ Incluso, la escasa cantidad de notas firmadas por periodistas de los diarios analizados puede deberse a dos causas: que no son producidas por periodistas científicos del medio o, en su defecto, que se trata de informaciones de las que se desconoce su productor y, por lo tanto, la rigurosidad de su abordaje.

$\mathrm{Al}$ analizar el comportamiento de dicha variable de manera pormenorizada según las distintas temáticas científicas, la forma de producción de la información en la mayoría de las disciplinas es análoga a la media de la muestra. Sin embargo, puede advertirse que en el caso de las informaciones correspondientes a Humanidades aumentan en grandes proporciones los casos donde se visibiliza la producción del periodista; en menor medida, por encima de la generalidad de la muestra, se ubican los ítems correspondientes a Salud.

Esta relación evidencia que la presencia del periodista científico es clave para el proceso de comunicación entre los medios, las fuentes y su público. Es decir, aquellos diarios digitales que cuentan con profesionales especializados producen contenidos informativos basados en mayor cantidad de fuentes. Tal como sostiene Mc Quail (1998), "habitamos una sociedad en la que los individuos y las instituciones dependen cada vez en mayor medida de la información y la comunicación para poder funcionar con eficacia en casi cualquier campo de actividad" (p. 25).

Además, ese nivel de producción periodística se corresponde con aquellos temas que la línea editorial considera de relevancia. En efecto, la producción noticiosa sobre ciencia es de mayor rigurosidad cuando es asumida por un profesional que accede a las fuentes científicas.

\footnotetext{
${ }^{12}$ Es necesario considerar que los diarios digitales analizados presentan artículos con firma en otras secciones o en otros ítems noticiosos, por lo que los resultados obtenidos constituyen un rasgo que hemos observado en estudios anteriores y no lo consideramos como una característica estilística del medio.
} 
Guillermo Damián Spina, Cecilia Beatriz Díaz

La cobertura de las noticias científicas en diarios digitales argentinos (2017-2018)

Por otra parte, el tipo del género periodístico elegido con mayor frecuencia por parte de los diarios generalistas es la noticia, lo que denota el poco espacio y profundidad del desarrollo de las aristas de la CPC. Esto puede atribuirse a que la ciencia adquiere noticiabilidad en tanto muestre resultados que afecten la vida cotidiana o el desarrollo económico regional, en detrimento de visibilizar los procesos de investigación.

Sin embargo, al observar el comportamiento de esta variable según el tipo de disciplina científica que se comunica, notamos que son las temáticas de Humanidades las que presentan el comportamiento más divergente a la media, tanto por su orden de ponderación como pluralidad de abordajes de géneros periodísticos. En cuanto a la primera, se observa que el reportaje es el formato más utilizado y es la especialidad que mayor utiliza la opción de la entrevista como forma de abordar la comunicación científica. La segunda temática, en consecuencia, es la que presenta una mayor proporción entre los géneros informativos.

También se destacan los casos de Salud y Agrarias, que evidencian una mayor presencia del formato reportaje, incluso por sobre la noticia. Sin embargo, la temática que presenta una mayor correspondencia con el tratamiento de la muestra anual es la vinculada a Económicas, donde prima la noticia como formato breve y de impacto.

Esta inferencia se complementa con la falta de diversidad de géneros en los que se presentan las noticias científicas. Esto puede atribuirse tanto a la combinación de las condiciones de producción periodística de los medios masivos como a la falta de adaptación de las novedades en el sector de contenidos noticiables, sumado a que son menores las consultas a los investigadores como fuentes de información en todos los diarios del país. Esto nos hace suponer que la distancia geográfica es relativa en su influencia: se trata de una distancia simbólica que se sostiene con respecto a trabajos anteriores (Spina, 2013; Spina y Díaz, 2017).

Este diagnóstico coincide con los resultados que marcan un amplio predominio de la fuente de tipo documental en las rutinas periodísticas, lo que podría inferir que la fuente escrita permite un desarrollo más simple y rápido para las dinámicas de actualización que exige la publicación online en detrimento de la consulta a la fuente humana a la que se debe entrevistar, o, más aún, si se decidiera utilizar ambas fuentes para generar un informe de mayor profundidad.

Asimismo, se observa que en la prensa digital argentina prima como criterio de selección de hechos noticiables aquellos que evidencian resultados científicos de utilidad concreta, como ocurre con los que se relacionan con temáticas de ciencias de la salud, economía o meteorología, las cuales despiertan el interés del lector (Spina y Díaz, 2018a).

En cuanto al tratamiento de fuentes, se observa que más de la mitad de los ítems analizados solo consultan una fuente y que el resto de las noticias no supera las cuatro. 
Esta situación llamaría la atención en el ámbito del periodismo generalista, donde el precepto es que cuanta más cantidad y calidad de fuentes haya, mayor es la credibilidad que se le da a la pieza periodística, al tiempo que se convierte en una variable que permite al lector descifrar la importancia que el medio otorga a la noticia publicada. No obstante, en el caso de la información científica, como afirman Olvera-Lobo y López-Pérez (2015), se está produciendo un fenómeno de homogeneización informativa, debido, en su mayor parte, al uso de revistas científicas y notas de prensa como fuente informativa.

Sin embargo, es pertinente reconocer que en el caso de las informaciones de disciplinas de Salud, Exactas y Naturales y Económicas se visibiliza una tendencia a utilizar más de una fuente.

Tal como se planteó en el marco teórico, la consulta a fuentes de distinta procedencia da cuenta de las relaciones entre los periodistas, los medios de comunicación y los sectores de la sociedad. Su frecuencia evidencia que son los sectores que cuentan con mayores recursos para desarrollar estrategias comunicacionales a fin de posicionarse como principales fuentes de información del periodismo. En ese sentido, se interpreta el predominio del Estado como tipo de fuente en los ítems analizados, seguido de las instituciones privadas.

Al respecto, podría inferirse que los distintos organismos públicos nacionales, provinciales y municipales cuentan con múltiples departamentos de prensa para elaborar informes y gacetillas dirigidas a las redacciones de los diarios digitales. Cabe mencionar que un aspecto de las prácticas de producción periodística es lo que se denomina en la jerga profesional: "refritar" la información recibida.

Otro caso lo constituyen las fuentes internacionales, que son dominantes en Ingenierías. Estas particularidades nos revelan signos de culturas compartidas entre medios y fuentes y de los posicionamientos de los agentes en el campo disciplinar y periodístico.

En cuanto al desagregado de la procedencia de las fuentes utilizadas, un aspecto destacable es que en cuanto a las nacionales, no son las universidades nacionales (solo el 5,5\%) ni los institutos privados argentinos (19\%) -ambos fuentes primarias de generación de información científica- las principales fuentes citadas, sino que es el Gobierno en sus distintos niveles y estructuras $(24,5 \%)$. De igual manera sucede si observamos las fuentes extranjeras, donde se repite este orden de ponderación.

Esto nos demuestra lo planteado por Nelkin (1990) respecto a la búsqueda de fuentes confiables en la ciencia: "La naturaleza de la ciencia favorece la confianza en las fuentes oficiales, fuentes previsibles y que saben preparar la información" (p. 126). De manera que la confianza en las fuentes oficiales se corresponde con la mayor aparición en los medios y no con el volumen de producción científica. 
Guillermo Damián Spina, Cecilia Beatriz Díaz

La cobertura de las noticias científicas en diarios digitales argentinos (2017-2018)

Esta característica se refuerza con los datos desagregados del tipo de procedencia de las fuentes, donde la mayoría de los casos de las fuentes estatales provienen de instancias gubernamentales y no de centros de investigación públicos. Esta falta de diversificación de la fuente científica remite al escaso desarrollo del periodismo científico como especialización en los diarios digitales argentinos.

Estos resultados parciales del estudio nos permiten ampliar los horizontes de reflexión sobre la producción noticiosa en las redacciones digitales de la prensa escrita de la Argentina. En esa línea, proponemos complementar los datos de este trabajo con análisis cualitativos sobre las condiciones de producción a los fines de contrastar estas inferencias, además de extender este estudio a otro tipo de contenidos digitales de carácter periodístico a los efectos de dar cuenta de un panorama más amplio del uso de los espacios destinados a reforzar el intercambio entre científicos, gobiernos, sociedad civil y sector empresarial. En suma, desde los medios ¿se considera a la información y al desarrollo científico como un contenido que puede ser de valor para la ciudadanía para afrontar y/o remediar problemáticas contemporáneas?

El aporte que intenta realizar la investigación en la que se inserta este trabajo es dar cuenta del estado de situación de la comunicación pública de la ciencia en los diarios digitales argentinos. En lo particular, este escrito destaca la escasa diversificación en el tratamiento de fuentes informativas que redunda en contenidos breves y de poca complejidad temática en la muestra nacional, al tiempo que revela que cuando hay interés editorial, se reconoce la autoría de los contenidos y se consultan más fuentes.

Este estado propicia un replanteo y una optimización de la relación entre instituciones, científicos y periodistas en pos de una comunicación pública de la ciencia más fructífera para la comunidad.

\section{Referencias}

Alcíbar Cuello, J. M. (2004). La divulgación mediática de la ciencia y la tecnología como recontextualización discursiva. Anàlisi: Quaderns de comunicació i cultura, (31), 43-70.

Alsina, M. R. (2003) Confianza en la información mediática. Revista Cidob d'afers internacionals, (61-62), 145-153.

Bajtín, M. (1979). Estética de la creación verbal. Buenos Aires: Siglo XXI.

Bauer, M. (2007). What we can learn from 25 years of PUS survey research? Liberating and expanding the agenda. Public understanding of Science, 16, 79-95.

Bauer, M. (2014). La sociedad de conocimiento favorece la comunicación de la ciencia, pero restringe la acción del periodismo científico. Revista Subjetividad y Procesos Cognitivos, 18(2), 53-70.

Bourdieu, P. (1996). Sobre la televisión. Barcelona: Anagrama. 
Austral Cmunicación

Volumen 9, número 1 (Junio de 2020): 5-43. ISSN 2313-9129

Bourdieu, P. (2003). El oficio de científico. Ciencia de la ciencia y reflexividad. Barcelona: Anagrama.

Bucchi, M. y Mazzolini, R. (2003). Big science, little news: science coverage in the Italian daily press, 1946-1997. Public understanding science, 12(1), 7-24.

Calvo Hernando, M. (2003). Divulgación y periodismo científico: entre la claridad y la exactitud. México: Universidad Nacional Autónoma de México.

Chimeno Rabanillo, S. (1997). Las fuentes, en el proceso de la información periodística especializada. En Esteve, F. (Coord.), Estudios sobre Información Periodística Especializada. Valencia: Fundación Universitaria CEU San Pablo.

Colombo, F. (1995). Últimas noticias sobre el periodismo. Manual de periodismo internacional. Barcelona: Anagrama.

Cortassa, C. (2011). La ciencia ante el público. Dimensiones epistémicas y culturales de la comprensión pública de la ciencia. Buenos Aires: Eudeba.

De-Semir, V. (2000). Periodismo científico, un discurso a la deriva. Revista Iberoamericana de discurso y sociedad, 2(2), 9-37.

Del Puerto, C. (2000) Periodismo científico: la astronomía en titulares de prensa. (Tesis doctoral). Facultad de Ciencias de la Información, Universidad de La Laguna.

Dimitrova, D. V., y Strömbäck, J. (2009). The Condicionality of Source Use: Comparing Source Use in U.S. and Swedish Television News. Journal of Global Mass Communication, 2(2), 149-166.

Domínguez, M. (2004). Singularidades de los géneros periodísticos en la divulgación de la ciencia. Quaderns de Filología, Estudis de Comunicació, (2), 163-172.

Dunwoody, S. (1986) The Scientist as Source en Friedman. En Friedman, S., Dunwoody, S. y Rogers, C. L. (Eds.), Scientists and Journalists, Reporting Science as News. Nueva York: Free Press.

Escudero Chauvel, L. (1997). ¿Quién es el autor de las noticias? Acerca del contrato mediático de la información. Revista Sociedad,(11).

Fayard, P. (1993). Science aux Quotidiens. Niza: Z’ Editions.

Franklin, B., y Carlson, M. (2011). Journalism, sources and Credibility. New Perspectives. Londres: Routledge.

Gans, H. (1979). Deciding what's News / A Study of CBS Evening News, NBC Nightly News and Time (Visions of the american press). Nueva York: Pantheon Books.

Gregori, J.(2004). El periodismo científico, hoy. Quark: Ciencia, medicina, comunicación y cultura, (34), 27-29.

Grossi, G. (2007). La opinión pública. Madrid: CIS.

Igartua, J. J. y Humanes, M. L. (2004). El método científico aplicado a la investigación en comunicación social. Portal de la Comunicación INCOM UB. Obtenido el 13 de marzo de 2012 de http://www.portalcomunicación.com/lecciones.asp?aut=11. 
Guillermo Damián Spina, Cecilia Beatriz Díaz

La cobertura de las noticias científicas en diarios digitales argentinos (2017-2018)

Irwin, A., y Michael, M. (2003). Science, social theory and public knowledge. Philadelphia: Open University Press, Maidenhead.

Krippendorf, K. (1990). Metodología de análisis de contenido. Teoría y práctica. Barcelona: Paidós.

Lacy, S., Robinson, K. y Riffe, D. (1995). Sample Size in Content Analysis of Weekly Newspapers. Journalism and mass communication quarterly, 72(2), 336-34.

Marín Murillo, F.y Armentia Vizuete,J.I.(2002).El periodismo científico en los diarios digitales del Estado español. Mediatika: Cuadernos de medios de comunicación, (8), 157-178.

Martini, S. (2000). Periodismo, noticia y noticiabilidad. Buenos Aires: Norma.

Martini, S., y Luchessi, L. (2004). Los que hacen la noticia. Periodismo, información y poder. Buenos Aires: Biblos.

Mayoral Sánchez, J. (2005). La batalla de las fuentes. Cuadernos de periodistas, (5), 9-16.

Mc Quail, D. (1998). La acción de los medios. Los medios de comunicación y el interés público. Buenos Aires: Amorrortu.

Miller, J., Pardo, R., y Niwa, F. (1998). Percepciones del público ante la ciencia y la tecnología. Estudio comparativo de la Unión Europea, Estados Unidos, Japón y Canadá. Bilbao: Fundación BBV.

Moreno Espinosa, P. (2010). Periodismo biomédico, nuevos contenidos mediáticos. Estudios sobre el Mensaje Periodístico, 16, 319-330.

Nelkin, D. (1990) La ciencia en el escaparate. Madrid: Fundesco.

Neuendorf, K. A. (2002). The content analysis guidebook. Thousand Oaks: Sage.

Olvera-Lobo, M. D.y López-Pérez,L.(2015). Periodismo científico: la homogeneización de la información del papel a internet. The Journal of Science Communication, 14(3), 2-12.

Palma, H. (2012). Infidelidad genética y hormigas corruptas: una crítica al periodismo científico. Buenos Aires: Teseo.

Ribas, C. (2002). El periodismo científico y su relación con el proceso de producción de las noticias en los medios de comunicación de masas. Madiatika: cuadernos de medios de comunicación, (8), 499-522.

Riffe, D., Lacy, S., y Fico, F. G. (2005). Analizing media messages: using quantitative content analysis in research. Londres: Lawrence Erlbaum Associates Publishers.

Ruiz de Elvira, M.(1990). Las fuentes de la noticia en ciencia. Arbor, ciencia pensamiento y cultura, (534-535), 93-102.

SECYT. (2006). Análisis de la oferta informativa sobre ciencia y tecnología en los principales diarios argentinos. Observatorio de Ciencia, Tecnología e Innovación productiva, Buenos Aires.

Spina, G. (2013). La comunicación pública de la ciencia en los medios gráficos argentinos. (Tesis de maestría). Universidad Nacional de La Matanza. 
Spina, G. D., y Díaz, C. B. (2016). Mapeo de la jerarquización de noticias sobre ciencia en los diarios generalistas de la Argentina (2015). Question, 1(51), 302-327.

Spina, G. D., y Díaz, C. B. (2017). Ciencia en diarios argentinos: temáticas y producción periodística en la prensa escrita generalista (2015). Chasqui Revista Latinoamericana de Comunicación, (135), 381-400.

Spina, G. D., y Díaz, C. B. (2018a). Jerarquización de las noticias sobre ciencia en los diarios digitales argentinos (2017-2018). Question, 1(61), 1-22.

Spina, G. D., y Díaz, C. B. (2018b). Estrategia metodológica para el estudio de la comunicación pública de la ciencia en diarios digitales argentinos. ENACOM 2018, Olavarría.

Spina, G. D., Díaz, C. B., Barberis, S. y Turriaga, L. (2018). Procedencia de las fuentes informativas sobre comunicación pública de la ciencia de los diarios argentinos. IV Jornadas de Estudios de América Latina y el Caribe, "América Latina: entre el asedio neoliberal y los desafíos emancipatorios", 14, 15 y 16 de noviembre de 2018, Buenos Aires, Argentina.

Stempel, G. H. (1989). Research methods in mass communication. Englewood Cliffs: Prentice hall.

UNESCO. (1999). Declaración sobre la Ciencia y el uso del saber científico. Budapest.

Van Dijk, T. (1990). La noticia como discurso, comprensión, estructura y producción de la información. Barcelona: Paidós

Verón, E. (1998) Entre la epistemología y la comunicación. CIC Cuadernos de Información y Comunicación, (4), 149-156.

Wolf, M. (1987) La investigación de comunicación de masas. Barcelona: Paidós. 